\title{
Mimicking the microbial oxidation of elemental sulfur with a biphasic electrochemical cell
}

\author{
Marco F. Suárez-Herrera ${ }^{\mathrm{a}, \mathrm{b}, *}$, Alonso Gamero-Quijano ${ }^{\mathrm{a}, \mathrm{d}}$, José Solla-Gullón ${ }^{\mathrm{c}}$, \\ Micheál D. Scanlon ${ }^{\mathrm{a}, \mathrm{d}, *}$ \\ a The Bernal Institute, University of Limerick (UL), Limerick V94 T9PX, Ireland \\ ${ }^{\mathrm{b}}$ Departamento De Química, Facultad De Ciencias, Universidad Nacional De Colombia, Cra 30 \# 45-03, Edificio 451, Bogotá, Colombia \\ ${ }^{\mathrm{C}}$ Instituto de Electroquímica, Universidad de Alicante, Ap.99, Alicante E-03080, Spain \\ d Department of Chemical Sciences, School of Natural Sciences, University of Limerick (UL), Limerick V94 T9PX, Ireland
}

\section{A R T I C L E I N F O}

\section{Article history:}

Received 4 June 2021

Revised 15 October 2021

Accepted 18 October 2021

Available online 22 October 2021

\section{Keywords:}

Sulfur oxidation

Polarised liquid|liquid interface

Interfacial assembly

Catalytic gold nanoparticles

Anion physisorption

\begin{abstract}
A B S T R A C T
The lack of an artificial system that mimics elemental sulfur $\left(\mathrm{S}_{8}\right)$ oxidation by microorganisms inhibits a deep mechanistic understanding of the sulfur cycle in the biosphere and the metabolism of sulfuroxidising microorganisms. In this article, we present a biphasic system that mimics biochemical sulfur oxidation under ambient conditions using a liquid|liquid (L/L) electrochemical cell and gold nanoparticles (AuNPs) as an interfacial catalyst. The interface between two solvents of very different polarity is an ideal environment to oxidise $\mathrm{S}_{8}$, overcoming the incompatible solubilities of the hydrophobic reactants $\left(\mathrm{O}_{2}\right.$ and $\left.\mathrm{S}_{8}\right)$ and hydrophilic products $\left(\mathrm{H}^{+}, \mathrm{SO}_{3}{ }^{2-}, \mathrm{SO}_{4}{ }^{2-}\right.$, etc. $)$. Furthermore, the interfacial AuNPs provide a catalytic surface onto which $\mathrm{O}_{2}$ and $\mathrm{S}_{8}$ can adsorb. Control over the driving force for the reaction is provided by polarising the L|L interface externally and tuning the Fermi level of the interfacial AuNPs by the adsorption of aqueous anions. Comparison of electrochemical measurements using a 4-electrode closed bipolar electrochemical cell and a $\mathrm{L} \mid \mathrm{L}$ electrochemical cell confirmed that electron transfer reactions are possible between $\mathrm{O}_{2}$, gold and $\mathrm{S}_{8}$ in biphasic systems.
\end{abstract}

(c) 2021 The Author(s). Published by Elsevier Ltd. This is an open access article under the CC BY license (http://creativecommons.org/licenses/by/4.0/)

\section{Introduction}

Sulfur and its species are important geochemical agents, with the sulfur cycle vital to maintaining the natural equilibrium of the biosphere. Most sulfur redox reactions in the biosphere are thermodynamically allowed but kinetically sluggish, requiring catalysis by microorganisms capable of using inorganic sulfur compounds in their metabolism, either as electron donors or acceptors [1]. Indeed, the earliest organisms on Earth gained energy from the metabolism of sulfur compounds, including elemental sulfur [2]. Technologically, microbiological sulfur oxidation underpins many industrial processes such as mineral biotechnology [1], microbial corrosion [3], decreasing the $\mathrm{pH}$ of alkaline soils [4] and the development of fertilisers [5]. Plants assimilate mainly sulfate ions, but there are many commercial fertilisers that contain sulfur in elemental form. Their effectiveness depends on the rate at which el-

\footnotetext{
* Corresponding authors at: The Bernal Institute, University of Limerick (UL), Limerick V94 T9PX, Ireland.

E-mail addresses: mfsuarezh@unal.edu.co (M.F. Suárez-Herrera), micheal.scanlon@ul.ie (M.D. Scanlon).
}

emental sulfur is oxidised to sulfate ions by microorganisms in the soil [6].

The most stable allotrope of elemental sulfur is $\alpha-S_{8}$. This highly hydrophobic element is neither wetted nor dissolved by water. The surface free energy of solidified sulfur ranges between 30 and $60 \mathrm{~mJ} \bullet \mathrm{m}^{-2}$, depending on the kind and age of the sulfur samples and/or the probe liquid used for the advancing and receding contact angle measurements [7]. The solubility of elemental rhombic sulfur in water is $1.9 \times 10^{-8} \mathrm{~mol} \cdot \mathrm{kg}^{-1}$ [7]. The standard reduction potential of $\mathrm{HSO}_{3}{ }^{-}$to sulfur is zero [8], which shows that the oxidation reaction of sulfur by molecular oxygen $\left(\mathrm{O}_{2}\right)$ is very likely from the thermodynamic point of view.

$\mathrm{HSO}_{3}^{-}+5 \mathrm{H}^{+}+4 e^{-} \rightarrow \mathrm{S}+3 \mathrm{H}_{2} \mathrm{O} E^{0}=0 \mathrm{~V}$

However, the kinetics of $\mathrm{S}_{8}$ oxidation by $\mathrm{O}_{2}$ are very slow at standard conditions for several reasons. The oxidation reaction is facilitated by the presence of water, which is a source of $\mathrm{H}^{+}$and $\mathrm{OH}^{-}$, but the solubility of $\mathrm{S}_{8}$ is very low in water and the wetting of $\mathrm{S}_{8}$ by water is poor. Additionally, to break the $\mathrm{O}_{2}$ double bond at room temperature is very difficult and the first ionisation energy of $\mathrm{S}_{8}$ is very high $(9.4 \mathrm{eV})$ [9]. To oxidise $\alpha-\mathrm{S}_{8}$, it has been proposed that microorganisms first dissolve it in the hydrophobic regions of their outer biomembranes. Subsequently, $\alpha-\mathrm{S}_{8}$ can be transported 
inside the cell by surfactants or react at the biomembrane|water interface [10]. In this context, many fundamental questions remain concerning the sulfur oxidation reaction and associated kinetics. Why is this reaction driven almost exclusively by microorganisms in the biosphere? Can a chemical pathway be designed for this reaction with a low activation energy and without the need of a biomolecule?

Biochemical reactions at a biomembrane interface are typically coupled to ion transfer and electron transfer chain reactions that either increase the electric field across the membrane or drive thermodynamically uphill reactions, like ATP synthesis [11]. A powerful approach to mimic and model such processes, involving simultaneous ion and electron transfer reactions, is to electrochemically polarise an interface between two immiscible electrolyte solutions (ITIES) [12-14]. Electrochemical reactions at such polarised liquid|liquid (L|L) interfaces can be complex as several charge transfer reactions may take place simultaneously (and be coupled), e.g., ion transfer, electron transfer, homogeneous chemical reactions, interfacial adsorption of ions or neutral species and the transport of solvent molecules across the interface by diffusion or facilitated by ion transfer [15].

The activation energy for $S_{8}$ oxidation in soils is between 60 and $100 \mathrm{~kJ} \cdot \mathrm{mol}^{-1}[1,16]$, which is relatively high considering that the oxidation of $S_{8}$ in soils is catalysed by microorganisms (acting as a biocatalyst). Thus, in the absence of a biocatalyst, the activation energy to form sulfate from $\mathrm{S}_{8}, \mathrm{O}_{2}$ and water is likely prohibitively high at ambient conditions. To our knowledge, the activation energy for $\mathrm{S}_{8}$ oxidation by $\mathrm{O}_{2}$ at ambient conditions in the absence of a catalyst has not been reported. Thus, a catalyst is required to generate a new chemical pathway to oxidise $S_{8}$ with low activation energy. Gold nanoparticles (AuNPs) [17] and nanoporous gold [18] are good catalysts for many oxidation reactions, despite the adsorption of $\mathrm{O}_{2}$ on macroscopic gold surfaces being unfavoured [19]. In particular, supported AuNPs show unusually high catalytic activity for carbon monoxide and alcohol oxidation by $\mathrm{O}_{2}$ [20]. On the other hand, Canfield [2] reported that $\mathrm{S}_{8}$ can be adsorbed on AuNP surfaces with cleavage of the S-S bond at a surface coverage $(\theta)<1 / 3$, while molecular adsorption takes place concurrently with atomic adsorption at $\theta>1 / 3$.

Complications arise when using supported AuNPs on a solid, as the nature of the solid support will affect the electronic state of the attached NPs [21]. Therefore, determining the specific effect of either the NPs size or their electronic structure on the kinetics of a reaction, for example for the $\mathrm{O}_{2}$ reduction reaction (ORR), becomes difficult. In this sense, a polarised $\mathrm{L} \mid \mathrm{L}$ interface functionalised with a film of AuNPs has some advantages when studying catalytic reactions. For example, there are two ways to change the Fermi level of NPs at a polarised L|L interface and tune their electronic state: by the adsorption of ions or in the presence of a redox pair in solution $[22,23]$. The past decade has seen a significant increase in activity to functionalise the polarised $\mathrm{L} \mid \mathrm{L}$ interface with various catalytic nanomaterials to study energy-related reactions [24], especially the ORR in the presence of AuNP films [25,26].

Herein, we describe a novel methodology to functionalise a polarised L|L interface with a film of AuNPs. This article provides the first experimental evidence of the physisorption of $\mathrm{Cl}^{-}$and $\mathrm{OH}^{-}$anions on such interfacial AuNPs. The oxidation reaction of elemental sulfur by $\mathrm{O}_{2}$ at a polarised $\mathrm{L} \mid \mathrm{L}$ interface catalysed by AuNPs is studied under ambient conditions and highlights the role of $\mathrm{OH}^{-}$ anions to enhance this oxidation reaction.

\section{Results and discussion}

\subsection{AuNP film growth at the polarised liquid|liquid interface}

The preparation of homogeneous and stable AuNP films at immiscible L|L interfaces is a major challenge $[25,27,28]$. Usually the surface is not homogeneously covered, significant aggregation of particles takes place at the interface, and potential cycling can induce movement of the particles generating an interfacial convection (interfacial stirring) [29]. Citrate ions are typically used to stabilise AuNP suspensions in bulk aqueous solutions [30]. However, such suspensions are very stable and, due to inter-particle electrostatic repulsion, the AuNPs rarely deposit in significant numbers at the L|L interface on contacting the aqueous phase with an immiscible organic solvent [31]. Various approaches have been demonstrated to weaken the electrostatic repulsion between AuNPs and induce interfacial deposition while retaining the constituent properties of the individual AuNPs to the greatest extent possible. These include functionalising the surfaces of charged colloidal NPs with charge-neutral organic "modifiers" [32,33] or adding amphiphilic salts to the biphasic system [34-36]. The latter act as "promoters" if the salts contain organic soluble ions of opposite charge to the NPs that screen inter-particle electrostatic repulsion [27].

Here, we replace the citrate buffer solution with a phosphatebuffered saline (PBS) solution, $\mathrm{pH} 7.4$, see electrochemical cell 1 in Scheme 1. The PBS-stabilised AuNP suspensions remain stable in the bulk aqueous phase. However, if these AuNPs come into proximity with a $\mathrm{L} \mid \mathrm{L}$ interface formed by water and $\alpha, \alpha, \alpha$ trifluorotoluene (TFT) they lose their ionic solvation shells, induced by the electric field at the interface and/or by changes of the local solvent polarity. In other words, PBS gives the dynamic freedom necessary to avoid agglomeration in the bulk aqueous phase but, at the same time, facilitates a change of the AuNPs ionic and solvation cloud at the $\mathrm{L} \mid \mathrm{L}$ interface.

Electrochemistry at $\mathrm{L} \mid \mathrm{L}$ interfaces facilitates AuNP film formation and provides a novel method to monitor and control the AuNP film growth using cyclic voltammetry (CV), see Fig. 1A. The adsorption of aqueous anions on the AuNPs gives a well-defined reversible signal between -0.2 and $+0.2 \mathrm{~V}$. With potential cycling, the amount of AuNPs at the interface increases, and so too does the adsorption of anions. This electrochemically driven experimental approach yields a homogeneous film of AuNPs and provides external control of the film thickness (Fig. 1B). The experiment was performed under an argon $(\mathrm{Ar})$ atmosphere as potential cycling in the presence of $\mathrm{O}_{2}$ can slowly oxidise the AuNPs irreversibly (discussed vide infra) and change the active surface where anion adsorption takes place.

\subsection{Physisorption of aqueous anions on the interfacial AuNPs}

The influence of the aqueous anion on the CV response of the interfacial AuNP film was probed by using either $10 \mathrm{mM} \mathrm{LiCl}$ or $10 \mathrm{mM} \mathrm{LiOH}$ as the aqueous phase under aerobic conditions (Fig. 2A). For both aqueous electrolytes, the near symmetric shape of the CVs and their behaviour with scan rate, showing a linear increase in peak current with scan rate (Fig. S1), indicate an interfacial adsorption/desorption process. Negatively charged AuNPs may attach and detach from the L|L interface with applied potential, but this process is very slow and does not yield symmetric voltammetry signals [28]. Therefore, the CV responses in Fig. 2A are attributed to the adsorption of ions on the interfacial AuNPs, specifically $\mathrm{OH}^{-}$and $\mathrm{Cl}^{-}$anions. CV responses for the adsorption of these anions at the bare $\mathrm{L} \mid \mathrm{L}$ interface do not give well defined peaks within the polarisable potential window. Fig. 2A and B show that the adsorption strength of $\mathrm{OH}^{-}$is much higher than that for $\mathrm{Cl}^{-}$, mirroring a trend observed for the electroadsorption of these ions on $\mathrm{Au}(111)$ [37].

The dotted lines in Fig. 2A show the results of computed numerical simulations of the $\mathrm{CV}$ profiles corresponding to an adsorption process following a Frumkin adsorption isotherm. The simulations solved the differential equation arising from the kinetics of the surface coverage in time upon potential cycling, the Python code is available in the Supporting Information (SI). The numer- 
Electrochemical cell 1

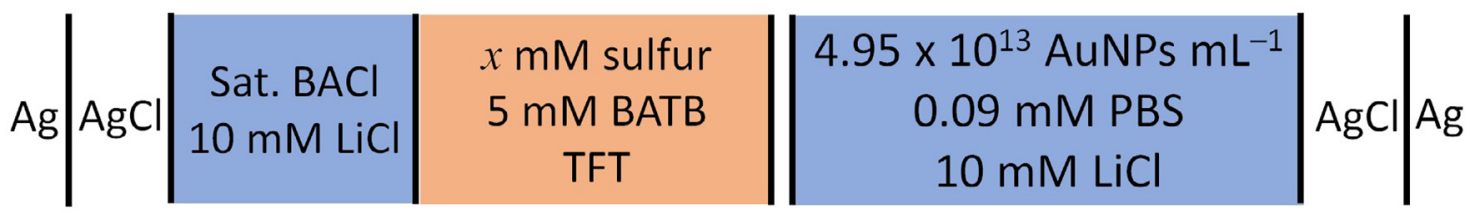

Electrochemical cell 2

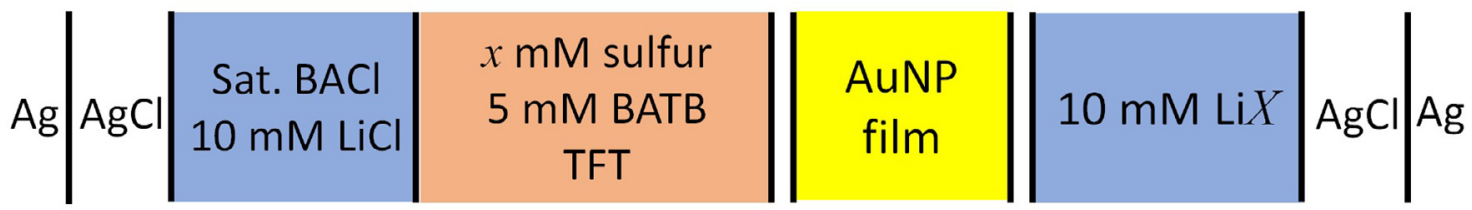

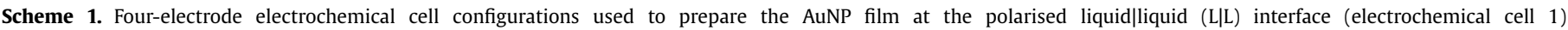

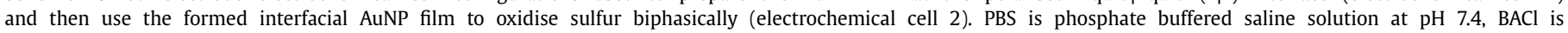

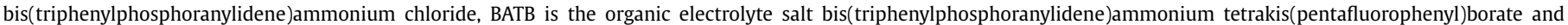
the organic solvent is $\alpha, \alpha, \alpha$-trifluorotoluene (TFT). The experiments were carried out either under aerobic or anaerobic conditions, as detailed in the text.
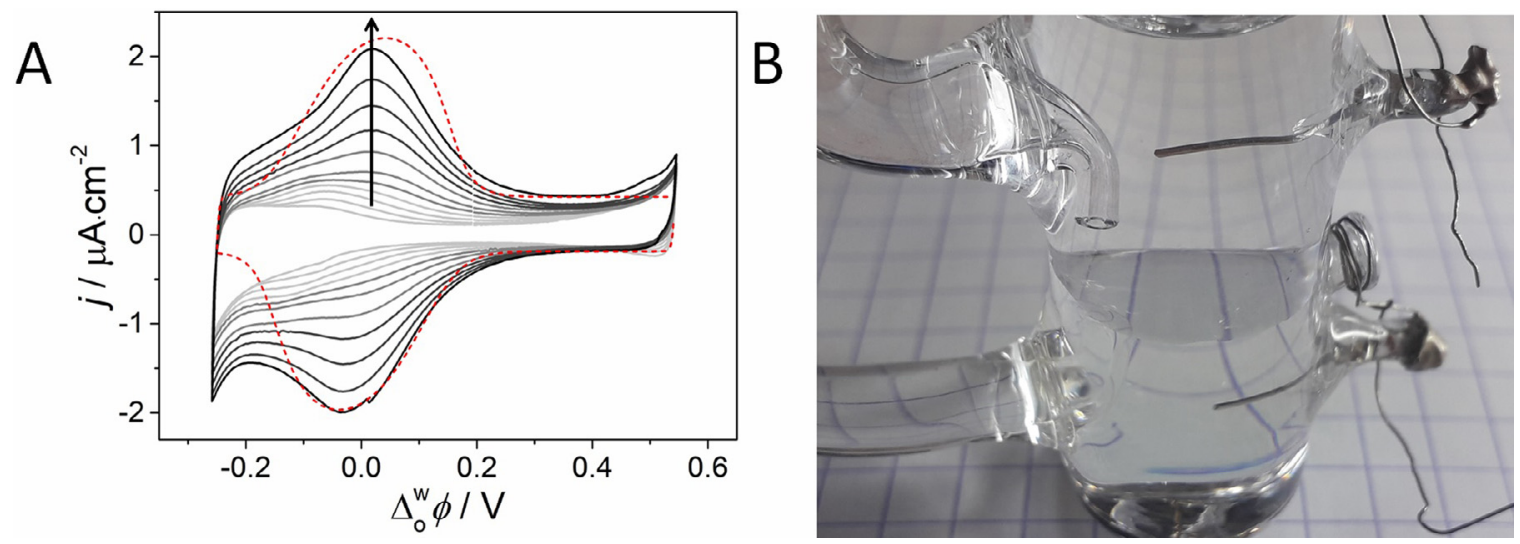

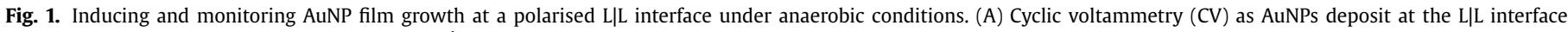

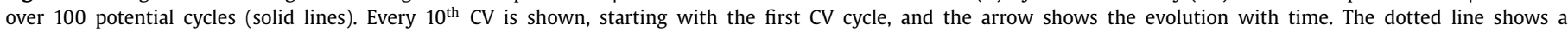

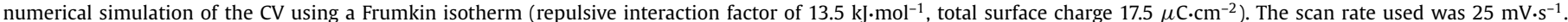

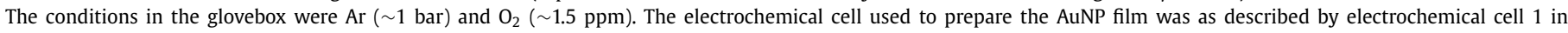

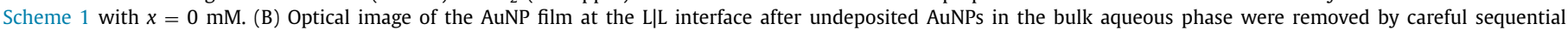
washing with $10 \mathrm{mM} \mathrm{LiCl}$. This image represents electrochemical cell 2 in Scheme 1 with $x=0 \mathrm{mM}$ and $X=\mathrm{Cl}^{-}$.

ical simulations show that the maximum charge density associated with $\mathrm{OH}^{-}$and $\mathrm{Cl}^{-}$adsorption during the negative scan are 24 and $12 \mu \mathrm{C} \cdot \mathrm{cm}^{-2}$, respectively. The simulations also show that the adsorption of anions can be reasonably described by a Frumkin model, where the Gibbs adsorption energy increases with surface coverage, with a repulsive interaction factor of $14.5 \mathrm{~kJ} \cdot \mathrm{mol}^{-1}$. The total maximum charge associated with $\mathrm{Cl}^{-}$adsorption is higher for AuNP films grown in an $\mathrm{Ar}$ atmosphere $\left(17.5 \mu \mathrm{C} \cdot \mathrm{cm}^{-2}\right.$, Fig. $\left.1 \mathrm{~A}\right)$ than in air $\left(12 \mu \mathrm{C} \cdot \mathrm{cm}^{-2}\right.$, Fig. $\left.2 \mathrm{~A}\right)$, and the CVs generated in an $\mathrm{Ar}$ atmosphere are more symmetric (Fig. 1A, black lines) than those in air (Fig. 2A, black line). The former suggests that the presence of $\mathrm{O}_{2}$ reduces the capacity of AuNPs to adsorb anions. On the other hand, the high value for the interaction factor, and the fact that it is almost the same for $\mathrm{OH}^{-}$and $\mathrm{Cl}^{-}$, suggests that after adsorption, the anions keep a significant negative charge. Thus, the anion-Au bond must be highly polar, and the CVs in Figs. $1 \mathrm{~A}$ and $2 \mathrm{~A}$ are due to the physisorption of anions, and not to their electro-adsorption. At the solid electrode|electrolyte interface, it is electro-adsorption and not physisorption of anions that is observed. The asymmetry between the negative and positive peaks shown in Fig. $2 \mathrm{~A}$ is due to (i) irreversible background transfer ionic currents [12], (ii) the partial oxidation of AuNPs and (iii) the slow kinetics of aqueous anion adsorption and desorption on the AuNPs (the desorption reaction is particularly slow). The long tail to the right of the positive peak in the presence of LiOH (Fig. 2A, solid red line) shows that the complete desorption of $\mathrm{OH}^{-}$is only achieved at $c a .+0.5 \mathrm{~V}$.

Oxide formation on $\mathrm{Au}(111)$ electrodes has been reported to occur when $\mathrm{OH}^{-}$adsorption reaches charge densities $>35 \mu \mathrm{C} \cdot \mathrm{cm}^{-2}$, meaning that this is the maximum $\mathrm{OH}^{-}$coverage that can be reached on $\mathrm{Au}$ [37]. Herein, the maximum coverage of $\mathrm{OH}^{-}$reached on the interfacial AuNPs is ca. $24 \mu \mathrm{C} \cdot \mathrm{cm}^{-2} \cdot \mathrm{OH}^{-}$is adsorbed more efficiently on a polarised Au electrode as the Fermi level of Au decreases when the $\mathrm{OH}^{-}$coverage increases with applied potential. In other words, the negative charge on adsorbed $\mathrm{OH}^{-}$is screened by a net charge transfer from the adsorbed anion to the Au electrode. On the other hand, $\mathrm{OH}^{-}$adsorption on the interfacial AuNPs increases their Fermi level. Thus, the AuNPs become more negatively charged, inhibiting the further adsorption of other $\mathrm{OH}^{-}$anions.

The influence of the aqueous anion on the measured differential capacitance curves in the presence of the AuNP film was also investigated (Fig. 2B). The capacitances in the presence of $\mathrm{LiCl}$ (black dots) and $\mathrm{LiOH}$ (red dots) were almost the same at potentials close to the potential of zero charge (PZC) around $+0.3 \mathrm{~V}$, confirming that the surface coverage of interfacial AuNPs was the same for 

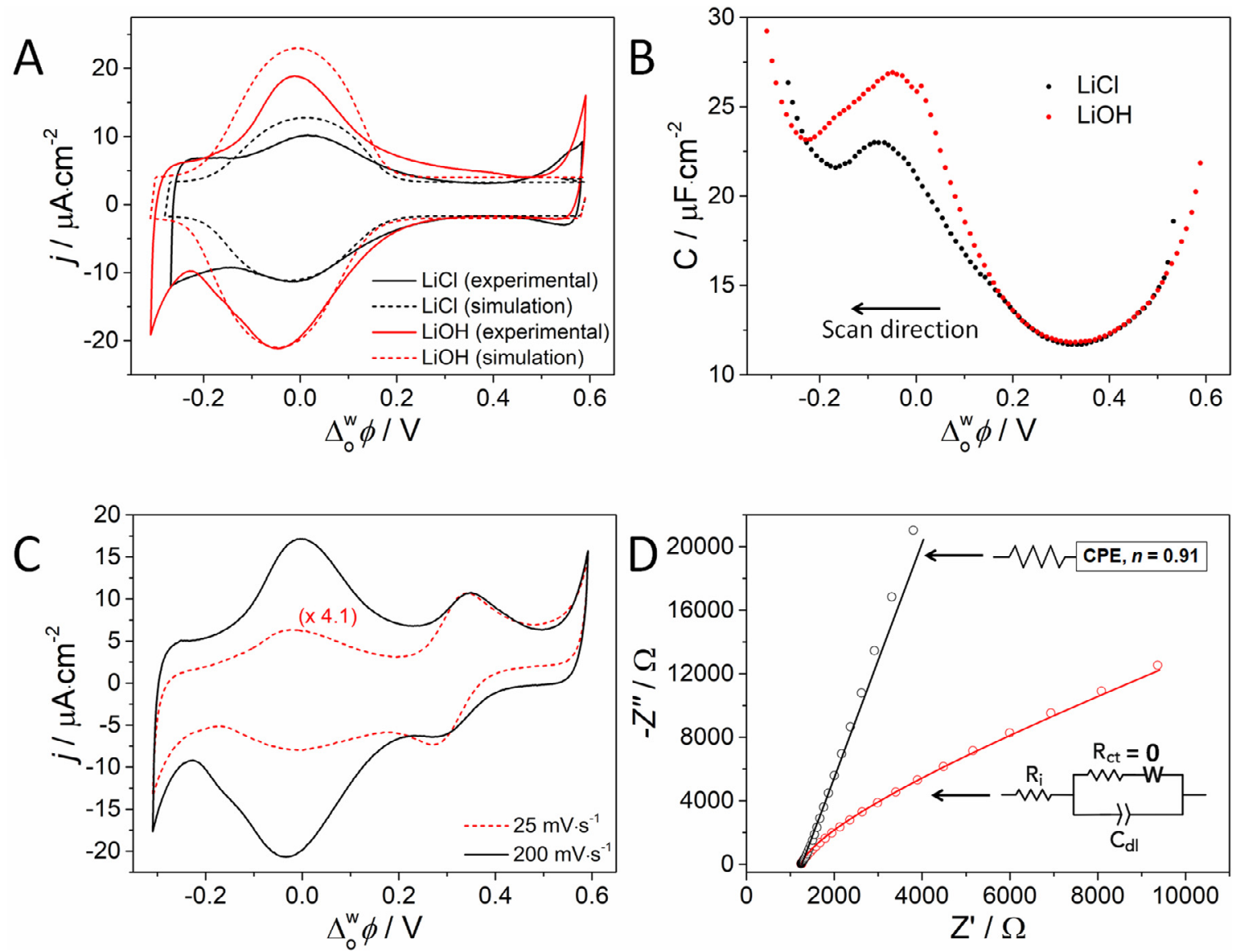

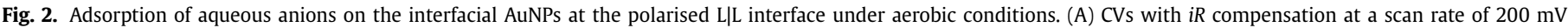

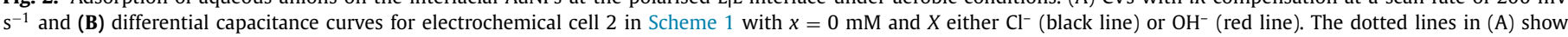

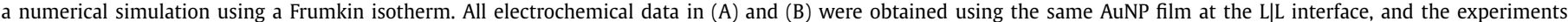

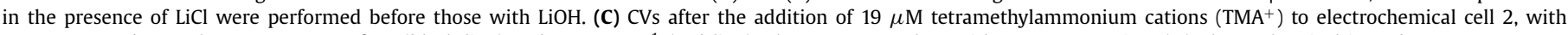

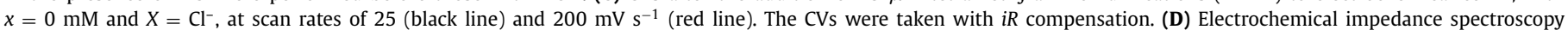

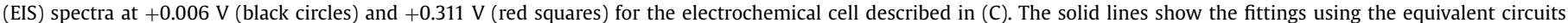
depicted (For interpretation of the references to color in this figure legend, the reader is referred to the web version of this article.).

both experiments and the AuNPs were stably attached to the interface. Furthermore, the well-defined peaks at potentials lower than the PZC confirm the adsorption of negatively charged anions. To our knowledge, this is first experimental evidence that $\mathrm{Cl}^{-}$and $\mathrm{OH}^{-}$ can be physisorbed, in their anionic form, on AuNPs at a polarised L|L interface.

The transparency of the interfacial AuNP film to ion transfer was investigated by monitoring the tetramethylammonium cation $\left(\mathrm{TMA}^{+}\right)$transfer reaction using CV and electrochemical impedance spectroscopy (EIS) at a AuNP film functionalised $\mathrm{L} \mid \mathrm{L}$ interface (Fig. 2C). Considering that $\mathrm{TMA}^{+}$transfers close to the PZC (compare Figs. 2B and C), a low influence of the electrical double layer was expected as the impact of migration should be negligible $[12,38]$. The interfacial AuNP film was found to have no significant effect on the $\mathrm{TMA}^{+}$ion transfer kinetics as demonstrated by (i) the peak separation of the reversible $\mathrm{TMA}^{+}$ion transfer response being $58 \mathrm{mV}$ (Fig. 2C), (ii) the ion transfer resistance being undetectable by EIS experiments (Fig. 2D), and (iii) the Randles circuit accurately describing the EIS spectra at the $\mathrm{TMA}^{+}$ion transfer potential of $+0.311 \mathrm{~V}$ (Fig. 2D).

The influence of scan rate on the signals associated with $\mathrm{Cl}^{-}$ and $\mathrm{OH}^{-}$adsorption or $\mathrm{TMA}^{+}$transfer is markedly different (Fig. $2 \mathrm{C}$ and Fig. S1). The peak current for the $\mathrm{Cl}^{-}$and $\mathrm{OH}^{-}$adsorption is proportional to the scan rate (Fig. S1D) and increases much faster with scan rate than the $\mathrm{TMA}^{+}$transfer signal, which is proportional to the square root of the scan rate (data not shown). Additionally, the EIS spectrum at $+0.006 \mathrm{~V}$ (Fig. 2D) shows that the AuNP film does not behave like an ideal capacitor, and a constant phase element (CPE) with an $n$ value of 0.91 is needed to fit the experimental data. Usually, a CPE with an $n$ value lower than 1 is associated with a capacitor comprising a very rough surface [39], surface energy heterogeneity [40], non-uniform current density inside porous films due to the "effective solution resistance" varying along the surface [41] and the distribution of kinetics adsorption rates across the interface [41]. Thus, this indicates that interfacial AuNP accumulation and agglomeration increases the roughness factor of the $\mathrm{L} \mid \mathrm{L}$ interface and/or there is a distribution of reaction rates across the AuNP film. Previously, Younan et al. showed that the capacitance of the $\mathrm{L} \mid \mathrm{L}$ interface increases in the presence of an adsorbed monolayer of citrate coated AuNPs and attributed this to an increase of the interfacial charge density or by an increase of the interfacial corrugation [42].

\subsection{Adsorption of hydrophobic elemental sulfur on the interfacial AuNPs}

The presence of $\mathrm{O}_{2}$ changes the active surface area of the interfacial AuNPs for the adsorption of anions (discussed vide supra when comparing Figs. $1 \mathrm{~A}$ and $2 \mathrm{~A}$ ). To further investigate this effect, the evolution of the CVs using electrochemical cell 2 with $\mathrm{LiOH}$ as the aqueous phase, see Scheme 1, under anaerobic conditions was probed (Fig. 3A). Extensive potential cycling clearly decreases 

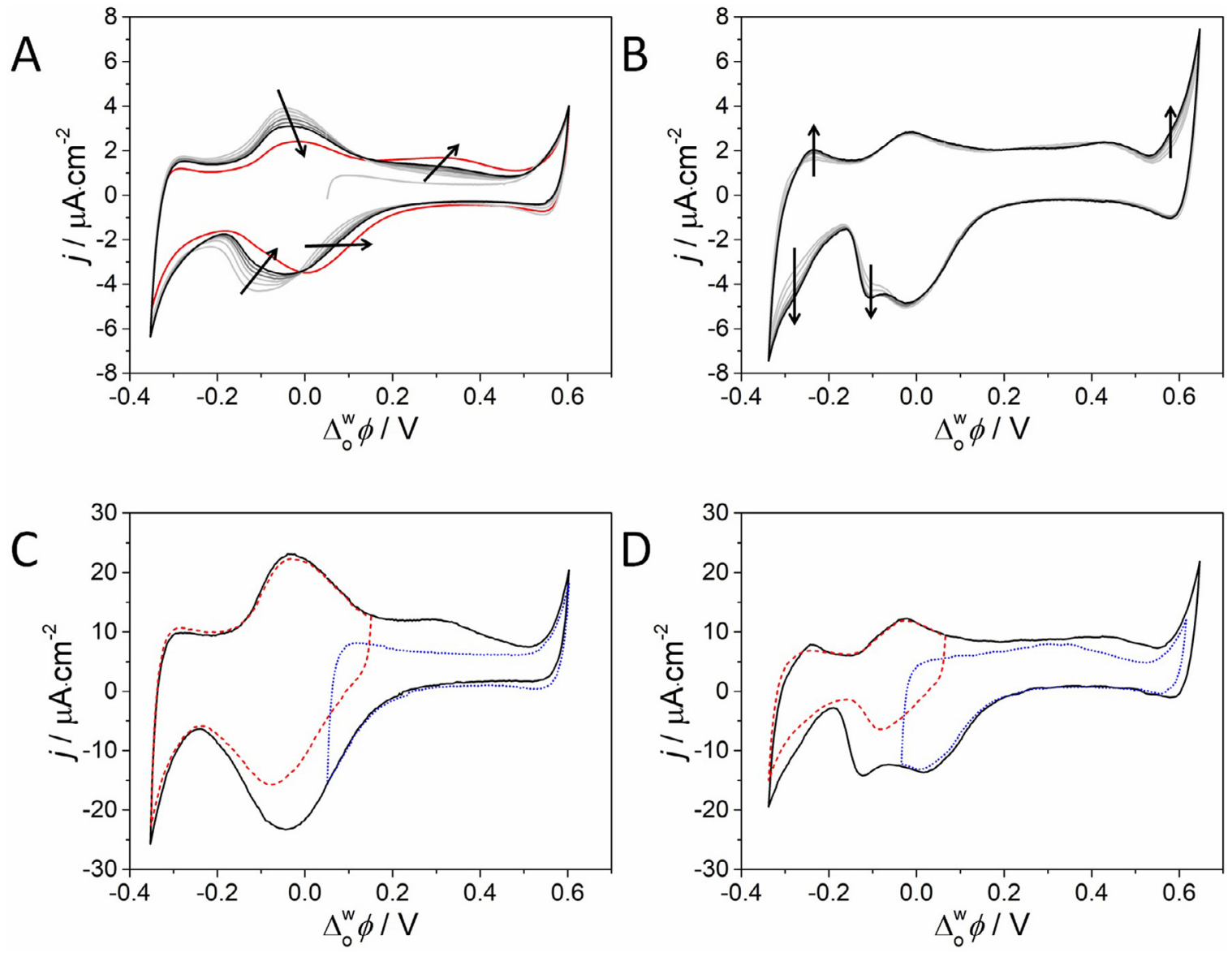

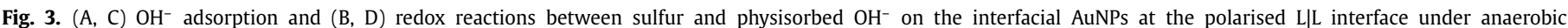

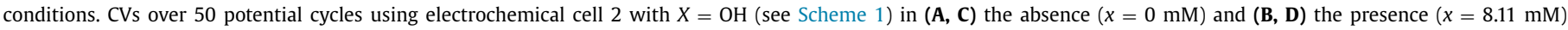

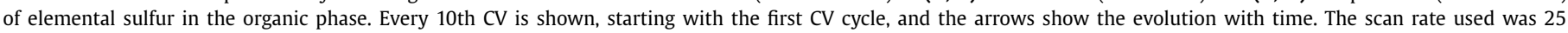

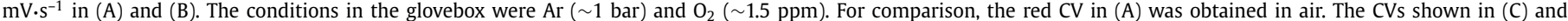

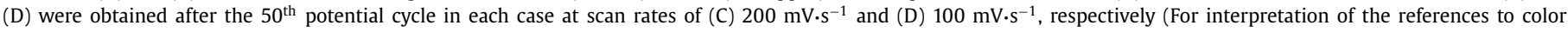
in this figure legend, the reader is referred to the web version of this article.).

the peaks related to $\mathrm{OH}^{-}$adsorption, generates a broad new signal between +0.1 and $+0.5 \mathrm{~V}$ and leads to the cathodic peak shifting to more positive potentials. Each of these changes are consistent with the CV obtained in air (red line in Fig. 3A), suggesting their origin as chemical reactions between $\mathrm{O}_{2}$ and AuNPs upon potential cycling. It seems that $\mathrm{O}_{2}$, even at very low concentrations $(\sim 1.5 \mathrm{ppm})$, slowly passivates the interfacial AuNPs surface, possibly by forming a layer of oxide upon extensive potential cycling.

The introduction of dissolved elemental sulfur to the organic phase stabilises the CVs when the cell is inside the glovebox, with some signals increasing slightly upon potential cycling (Fig. 3B). Interestingly, the CVs shown in Fig. 3B are similar to those reported for aqueous solutions of $\mathrm{Na}_{2} \mathrm{~S}$ in alkaline media on Au electrodes [43-45] and, in our opinion, can be rationalised in a similar way. Firstly, previous studies have indicated that both atomic and molecular sulfur can be adsorbed on gold [44-46]. Secondly, the shape and behaviour of the CVs with scan rate suggests that the peaks observed inside the potential window arise mainly from surface processes. Thirdly, the asymmetry of the CVs in Fig. 3B, where the negative peaks are higher than the positive peaks, suggests that an irreversible chemical reaction occurs during the potential scans. In this sense, we suggest that the following reactions are taking place in Fig. 3B:

$\mathrm{OH}^{-}(\mathrm{aq}) \rightleftarrows \mathrm{OH}^{-}(\mathrm{ad})$

$2 \mathrm{OH}^{-}(\mathrm{ad})+\mathrm{S}(\mathrm{ad}) \rightleftarrows 2 \mathrm{OH}(\mathrm{ad})+\mathrm{S}^{2-}(\mathrm{ad})$
$2 \mathrm{OH}^{-}(\mathrm{ad})+\mathrm{S}_{x}(\mathrm{ad}) \rightleftarrows 2 \mathrm{OH}(\mathrm{ad})+\mathrm{S}_{x}^{2-}(\mathrm{ad})$

where (ad) means adsorbed on the interfacial AuNPs' surface and (aq) means on the aqueous side of the interface.

The reduction of atomic $(S)$ or molecular $\left(S_{x}\right)$ sulfur adsorbed on the interfacial AuNPs can be promoted by the adsorption of $\mathrm{OH}^{-}$ Eqs. (2) to ((4)), leading to an additional negative peak between 0.15 and $+0.2 \mathrm{~V}$ in the presence of sulfur (Fig. 3D). The potential windows were reduced in Figs. $3 \mathrm{C}$ and $3 \mathrm{D}$ to highlight (i) a reversible signal due to $\mathrm{OH}^{-}$physisorption is seen in both CVs (red lines) and (ii) an irreversible signal is seen in the presence of either $\mathrm{O}_{2}$ or sulfur (blue lines). The blue signals in Fig. 3D can be attributed to a redox reaction between sulfur and adsorbed $\mathrm{OH}^{-}$.

Differential capacitance curves in the absence of sulfur in the organic phase further support the fact that $\mathrm{O}_{2}$ modified the AuNP's surface, with the capacitance under aerobic conditions being higher (Fig. 4A). The AuNP's surface is usually oxide-free under ambient conditions. However, in alkaline media, such as the $\mathrm{LiOH}$ aqueous phase used in Fig. 4A, gold oxidation proceeds at lower potentials, and therefore, the formation of gold oxides upon potential cycling leads to higher capacitances [47]. Another possibility for the origin of the gold passivation process can be an irreversible reaction between $\mathrm{O}_{2}$ and unidentified contaminants present in the organic phase.

The differential capacitance curves change significantly with the scan direction in the presence of sulfur in the organic phase under 

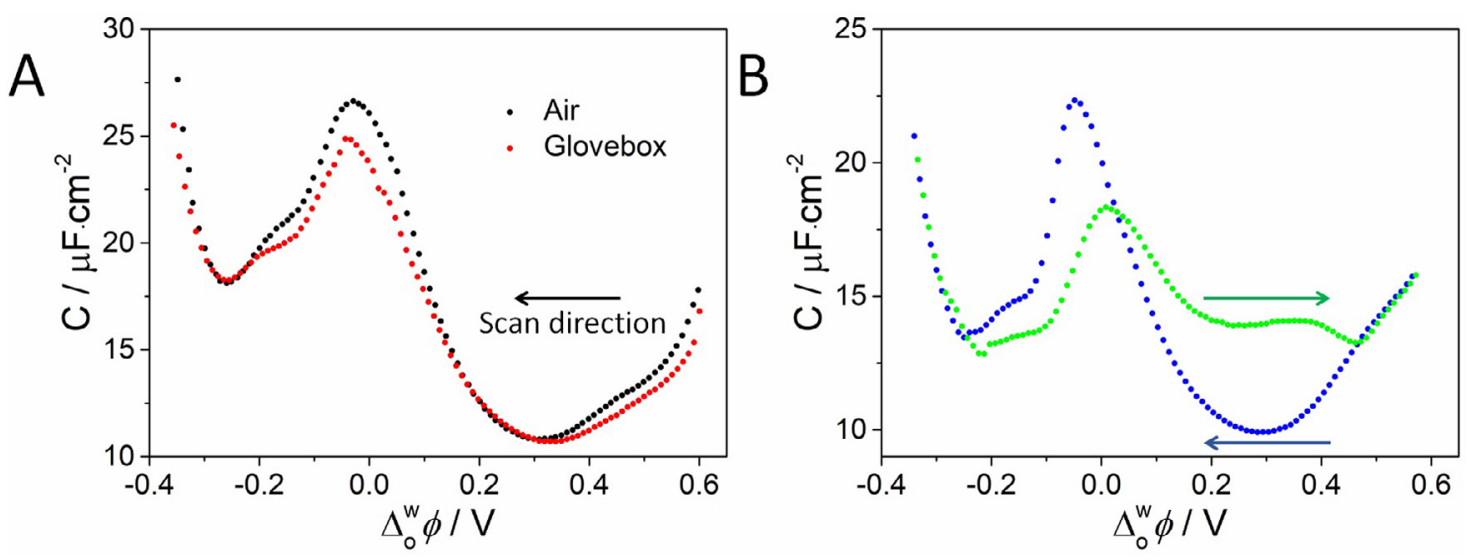

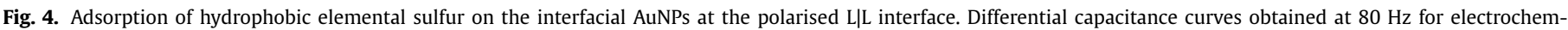

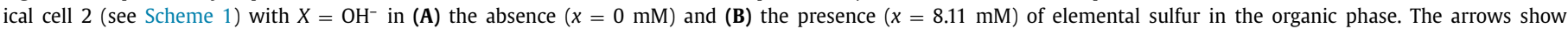

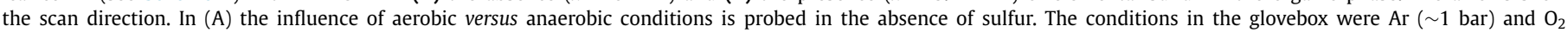

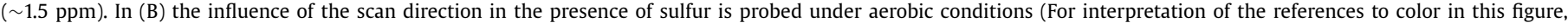
the reader is referred to the web version of this article.).

aerobic conditions (Fig. 4B). This demonstrates that the chemical composition of the AuNP's surface at the same potential depends on the scan direction and that surface chemical reactions are taking place on this surface. The capacitances are near identical at the extremes of the potential window but, at potentials close to the PZC $(c a .+0.3 \mathrm{~V})$, the capacitances are lower for the negative scan direction than those for the positive scan direction. The adsorption of a hydrophobic and neutral species like $\mathrm{S}_{8}$ is more likely close to the PZC because the gold surface is "clean" and more hydrophobic at the PZC. Therefore, we attribute the lower capacitance close to the PZC during the negative scan to atomic and molecular sulfur adsorption on the interfacial AuNPs (blue circles, Fig. 4B). At extremely negative or positive potentials, the AuNP's surface is hydrophilic and the adsorption of $\mathrm{S}_{8}$ is unlikely. Furthermore, $\mathrm{S}_{8}$ does not adsorb on the interfacial AuNPs scanning positively as their surface has already been coated in adsorbed $\mathrm{OH}^{-}$species and is too hydrophilic.

The adsorption of $S_{8}$ scanning negatively agrees with the observation that the peak between $-0.2 \mathrm{~V}$ and $+0.2 \mathrm{~V}$ is higher for the negative scan direction curve (blue circles, Fig. 4B). This behaviour may come from pseudo-capacitance currents due to the reduction of adsorbed sulfur, with the simultaneous oxidation of adsorbed $\mathrm{OH}^{-}$, i.e., currents coming from reversible or quasireversible electron transfer reactions due to the simultaneous reduction of adsorbed sulfur and oxidation of $\mathrm{OH}^{-}$ions at the organic and aqueous sides of the AuNP film, respectively. Such changes were not observed with the scan direction in the absence of sulfur under aerobic conditions (data not shown).

\subsection{Biphasic oxidation of elemental sulfur catalysed by interfacial AuNPs at a polarised $L \mid L$ interface}

The influence of the presence of sulfur in the organic phase on the evolution of the CVs as the AuNP film is formed with potential cycling under aerobic conditions is shown in Fig. 5A. The presence of both AuNPs in the aqueous phase and sulfur in the organic phase (Fig. 5A and B, black solid line) leads to an increase in current over the whole potential window in comparison to otherwise identical experiments either in the absence of the AuNPs (Fig. 5B, red dash-dot line) or sulfur (Fig. 5B, blue dashed line). The increase in current and irreversibility of the signal suggests an irreversible redox reaction between sulfur and dissolved $\mathrm{O}_{2}$, catalysed by the interfacial AuNPs, is taking place.
To study the oxidation of sulfur on a well-defined interfacial AuNP film, after the experiment shown in Fig. 5A was complete, all suspended AuNPs were removed from the aqueous phase and replaced with pure $10 \mathrm{mM} \mathrm{LiCl}$ by sequential washing steps. The $\mathrm{CV}$ of this electrochemical cell is shown in Fig. 5C (red line) and is identical to the CV shown in Fig. 5B (black line). However, a remarkable increase of current over the whole potential window occurs when $\mathrm{LiOH}$ replaced the $\mathrm{LiCl}$ aqueous phase through a further sequential washing step (Fig. 5C, black line). The $\mathrm{OH}^{-}$anions significantly enhance the redox reactions that are taking place, which we attribute to low-temperature sulfur oxidation at a polarised $\mathrm{L} \mid \mathrm{L}$ interface in the presence of interfacial AuNPs. It is important to state that the $\mathrm{pH}$ not only affects the adsorption of $\mathrm{O}_{2}$ on the AuNPs, but also the speciation and stability of sulfur and its oxidation products [48]. It is also noted that the CV in Fig. 5C with LiOH (black line) under aerobic conditions is markedly different to the CVs in Fig. 3B obtained under anaerobic conditions, using otherwise identical experimental conditions.

The signals $R$ and $O$ in Fig. 5D are related to irreversible processes and grow upon potential cycling. The latter indicates that a redox reaction is taking place and the concentration of reactive intermediaries increases with time. This is the behaviour expected for biphasic $S_{8}$ oxidation, where intermediaries such as thiosulfate, sulfite and sulfate anions are formed and transferred irreversibly to the aqueous phase. The complexity of the processes taking place at the interface is highlighted by the many signals observed across the full potential window (see insert, Fig. 5D), likely due to ion transfer of sulfur oxidation products to the aqueous phase such as polythionates, dithionate, dithionite, thiosulfate, etc. These ions transfer within the available potential window at the polarised $\mathrm{L} \mid \mathrm{L}$ interface due to their low charge densities and high solubilities in both the aqueous and organic phases. However, their analytical detection directly at the interface is extremely challenging due to their instabilities' in low temperature aqueous systems with respect to sulfide, sulfate and elemental sulfur species [49].

The role of $\mathrm{OH}^{-}$to enhance the catalytic activity of AuNPs towards oxidation processes, such as the enhanced currents attributed to $\mathrm{S}_{8}$ oxidation in Fig. $5 \mathrm{C}$ and $\mathrm{D}$ when $\mathrm{LiOH}$ is the aqueous electrolyte, has precedent in the literature. For example, supported AuNPs have higher catalytic activity for the oxidation of carbon monoxide and alcohol at alkaline rather than acidic pHs [20]. Adsorbed $\mathrm{OH}^{-}$plays key roles in three processes critical to the oxidation process: the adsorption of $\mathrm{O}_{2}$ on the AuNPs, as an intermediary and as a source of oxygen atoms [20]. Furthermore, 

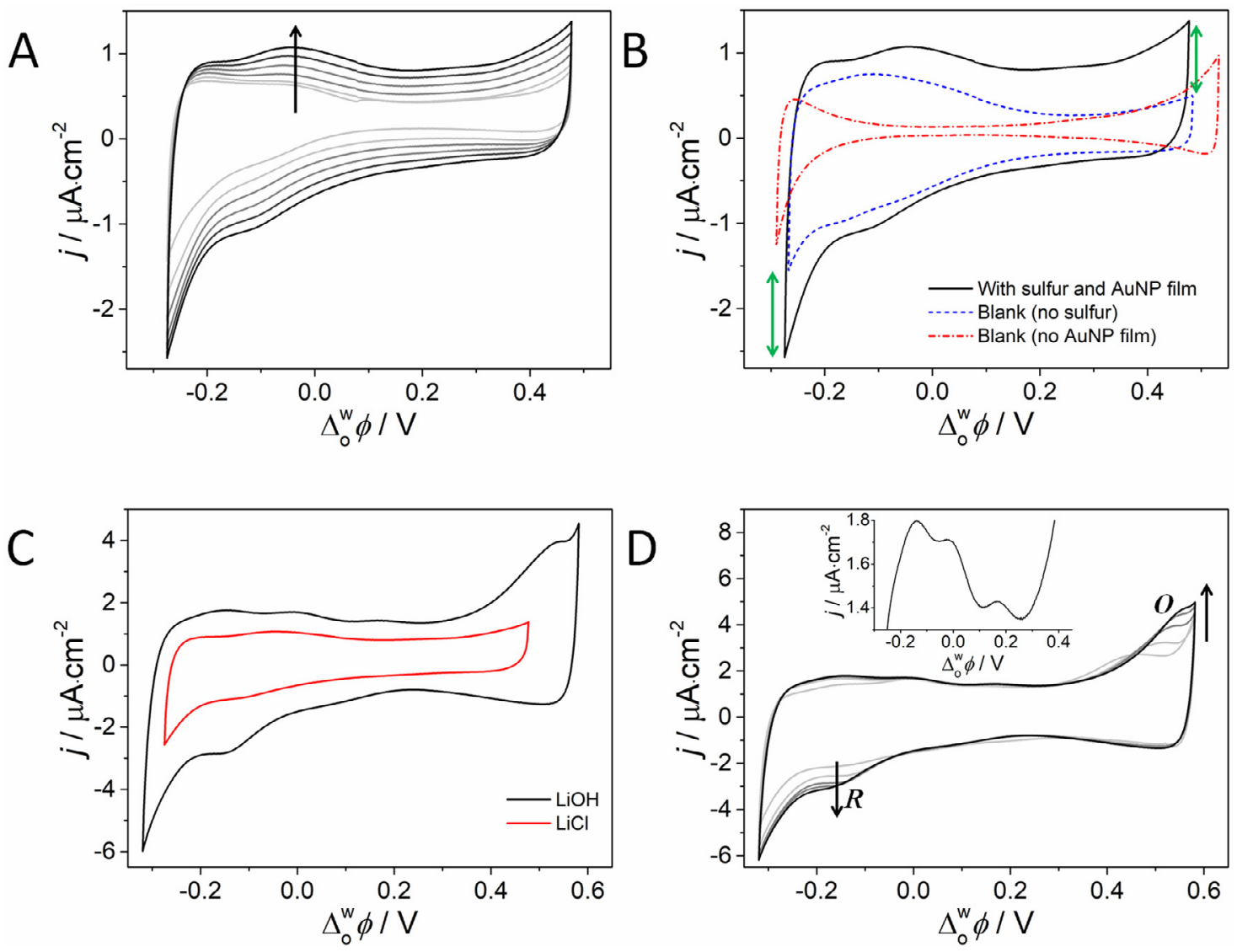

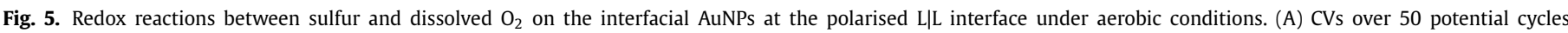

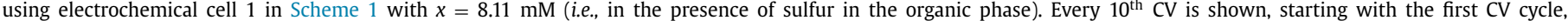

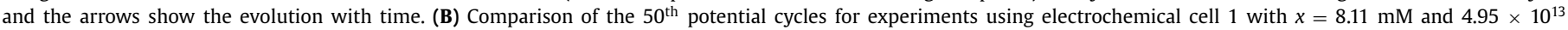

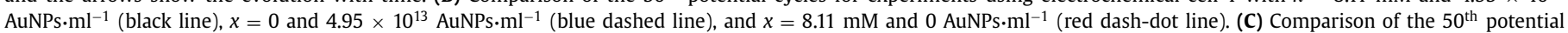

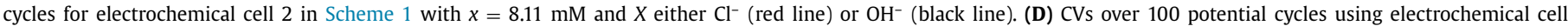

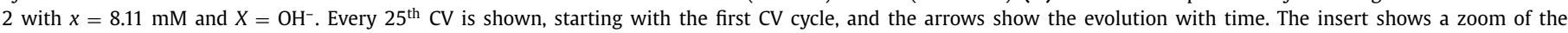

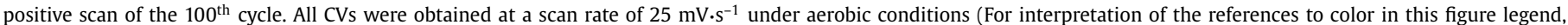
the reader is referred to the web version of this article.).

Huang et al. reported that oxygen anions $\left(\mathrm{O}_{2}{ }^{-}\right)$are preferentially adsorbed on AuNPs compared with $\mathrm{O}_{2}$ [50]. Thus, the adsorption of $\mathrm{OH}^{-}$, or $\mathrm{Cl}^{-}$, can promote the adsorption of $\mathrm{O}_{2}$ by charging the AuNP's surface negatively. The latter increases the negative charge of $\mathrm{O}_{2}$ upon adsorption. This explanation is the same as that used to understand the adsorption of $\mathrm{O}_{2}$ on ionic solids, where charge transfer from the support to the AuNPs is required to enhance the ORR on gold [51].

Experimental evidence strongly suggests that the adsorption and reduction of $\mathrm{O}_{2}$ on AuNPs is more likely to occur through proton-coupled electron transfer (PCET) reactions. For example, using surface-enhanced infrared absorption spectroscopy (SEIRAS), Ohta et al. reported the presence of adsorbed $\mathrm{O}_{2}\left(\mathrm{O}_{2}(\mathrm{ad})\right)$ and hydrogen superoxide $\left(\mathrm{HO}_{2}(\mathrm{ad})\right)$ during the ORR on $\mathrm{Au}(111)$ electrode in aqueous perchloric acid [52]. Also, Shao and Adzic reported the presence of adsorbed $\mathrm{HO}_{2}{ }^{-}$in the potential range where the ORR occurs in alkaline media [53].

An open question is: does the ORR take place on the aqueous or organic side of the L|L interface? [26]. No definitive statement can yet be made in this regard; however we can make some inferences based on the relative solubilies of $\mathrm{O}_{2}$ in water and organic solvents. To our knowledge, the solubility of $\mathrm{O}_{2}$ in TFT has yet to be reported, but it will be similar to that in solvents such as toluene or benzene. The solubility of $\mathrm{O}_{2}$, in terms of mole fraction of $\mathrm{O}_{2}$ in solution, is $2.301 \times 10^{-5}$ for water and $9.23 \times 10^{-4}$ for toluene at $298.15 \mathrm{~K}$ (i.e., 40 times higher than in water) [54]. Nev- ertheless, in Section 2.7 vide infra, we demonstrate that $\mathrm{O}_{2}$ can be reduced on either side of the $\mathrm{L} \mid \mathrm{L}$ interface depending on the electrochemical potential of $\mathrm{O}_{2}$ in that phase. In this sense, we analyse both scenarios where $\mathrm{O}_{2}$ is either on the organic (Section 2.5) or aqueous (Section 2.6) side of the L|L interface, respectively.

Comparing Figs. $1 \mathrm{~A}$ and $5 \mathrm{D}$, the presence of sulfur, $\mathrm{O}_{2}$ and many reaction intermediaries clearly affect the reversible adsorption of ions, leading to the adsorption currents disappearing. The latter may be due to some intermediaries competing with (or blocking) anion adsorption and/or affecting the AuNP agglomeration process, and thus the structure of the AuNP Film. The adsorption currents may also be hidden by currents that come from electron transfer reactions.

\subsection{Tuning the Fermi level of the AuNPs by varying the interfacial Galvani potential difference}

The interfacial Galvani potential difference $\left(\Delta_{0}^{\mathrm{w}} \phi\right)$ affects both the thermodynamics and kinetics of all chemical reactions where ionic species are involved. For example, let's consider the following reaction:

$\mathrm{OH}^{-}$(aq) $+\mathrm{O}_{2}$ (org) $\rightarrow \mathrm{OH}($ ad $)+\mathrm{O}_{2}^{--}$(org)

The electrochemical potentials of the ionic species are:

$\tilde{\mu}_{\mathrm{OH}^{-}(\mathrm{aq})}=\mu_{\mathrm{OH}^{-}(\mathrm{aq})}^{0}+R T \ln a_{\mathrm{OH}^{-}(\mathrm{aq})}-F \phi_{\mathrm{aq}}$ 
$\tilde{\mu}_{\mathrm{O}_{2}^{-} \text {(org) }}=\mu_{\mathrm{O}_{2}^{-} \text {(org) }}^{0}+R T \ln a_{\mathrm{O}_{2}^{-} \text {(org) }}-F \phi_{\mathrm{org}}$

In this sense, the change of free energy of reaction (5) is:

$\Delta \tilde{G}=\Delta G-F\left(\phi_{\text {org }}-\phi_{\text {aq }}\right)=\Delta G+F \Delta_{\mathrm{o}}^{\mathrm{w}} \phi$

where $\Delta G$ is the total change of the chemical potential. Eq. (8) shows that interfacial polarisation with a negative $\Delta_{0}^{\mathrm{w}} \phi$ makes reaction (5) more likely. The latter leads to enhanced adsorption of $\mathrm{OH}^{-}$on the AuNPs' surface and, thus, an increase in the Fermi level of the interfacial AuNPs, $E_{\mathrm{F}}$ (AuNPs). Furthermore, a negative $\Delta_{0}^{\mathrm{w}} \phi$ increases the activity of $\mathrm{OH}^{-}(\mathrm{aq}), a_{\mathrm{OH}^{-}(\mathrm{aq})}$, thereby increasing the chemical potential of $\mathrm{OH}^{-}$on the aqueous side of the interface and also increasing the driving force of reaction (5).

Under the approximation of the Butler-Volmer equation, the electron transfer kinetic constant, $k$, for the ORR:

$\mathrm{O}_{2}(\mathrm{org})+e^{-} \rightarrow \mathrm{O}_{2}^{--}(\mathrm{ad})$

is:

$k=k^{0} \exp \left(\frac{\alpha F\left(E_{F}(\text { AuNPs })-E^{0}\right)}{R T}\right)$

Taking into account that $\Delta_{\mathrm{o}}^{\mathrm{w}} \phi$ affects $E_{\mathrm{F}}$ (AuNPs), as discussed due to the adsorption of $\mathrm{OH}^{-}$, it is going to also affect the kinetics of the electron transfer reactions according to Eq. (10).

Considering that $E_{\mathrm{F}}$ (AuNPs) increases at negative $\Delta_{\mathrm{o}}^{\mathrm{w}} \phi$ to favour reduction reactions in the organic phase, and the likely favoured PCET pathway for the ORR on the AuNPs surface, we propose that the irreversible signal $R$ at a negative $\Delta_{0}^{\mathrm{w}} \phi$ in Fig. 5D is related to some or all of the following reactions:

$\mathrm{O}_{2}(\mathrm{org})+\mathrm{OH}^{-}(\mathrm{ad}) \rightarrow \mathrm{O}_{2}^{--}(\mathrm{ad})+\mathrm{OH}(\mathrm{ad})$

$\mathrm{O}_{2}^{--}(\mathrm{ad})+\mathrm{H}_{2} \mathrm{O}(\mathrm{ad}) \rightarrow \mathrm{HO}_{2}^{-}(\mathrm{ad})+\mathrm{OH}(\mathrm{ad})$

$\mathrm{HO}_{2}^{-}(\mathrm{ad})+\mathrm{H}_{2} \mathrm{O}(\mathrm{ad}) \rightarrow 2 \mathrm{OH}(\mathrm{ad})+\mathrm{OH}^{-}(\mathrm{ad})$

These reactions can be seen in general as the electroadsorption of $\mathrm{OH}^{-}$coupled to $\mathrm{O}_{2}$ reduction. At this point, it is important to state that, in the presence of both $\mathrm{O}_{2}$ and $\mathrm{S}_{8}$, the reduction of $\mathrm{O}_{2}$ rather than the reduction of sulfur is more likely from a thermodynamic viewpoint. The standard reduction potential in aqueous media of $\mathrm{O}_{2}$ to water is $+1.23 \mathrm{~V}$ and the reduction potential of sulfur to $\mathrm{H}_{2} \mathrm{~S}$ is $+0.14 \mathrm{~V}$. We assume that this trend is the same in organic solvents like TFT.

At positive $\Delta_{\mathrm{o}}^{\mathrm{w}} \phi, E_{\mathrm{F}}$ (AuNPs) lowers sufficiently due to the desorption of $\mathrm{OH}^{-}$to favour oxidation reactions in the organic phase. Thus, we propose that the irreversible signal $O$ in Fig. $5 \mathrm{D}$ is related to sulfur oxidation. The first step of $S_{8}$ oxidation can be the reaction:

$\mathrm{S}_{8}(\mathrm{ad})+\mathrm{OH}(\mathrm{ad}) \rightarrow \mathrm{S}_{8}^{+}(\mathrm{ad})+\mathrm{OH}^{-}(\mathrm{aq})$

However, a more likely scenario is that adsorbed sulfur atoms can be oxidised as follows:

$\mathrm{S}(\mathrm{ad})+\mathrm{OH}(\mathrm{ad})+\mathrm{H}_{2} \mathrm{O}+\mathrm{O}_{2}^{--}(\mathrm{ad}) \rightarrow \mathrm{H}_{2} \mathrm{SO}_{3}+\mathrm{OH}^{-}(\mathrm{aq})$

2.6. The effect of the interfacial Galvani potential difference on the ORR when $\mathrm{O}_{2}$ is on the aqueous side of the L|L interface

Let's consider that the reactions described in Eqs. (11) to (13) take place on the surface of the AuNPs at the aqueous side. In this case, all reactants of reaction (11) are on the same side of the interface meaning $\Delta_{0}^{\mathrm{w}} \phi$ has no effect on the kinetic constants of the electron transfer reactions. However, $\Delta_{0}^{\mathrm{w}} \phi$ will affect the thermodynamic properties (reduction potentials) and reaction rates as it affects the reactants' interfacial activities. For example, reaction (11) can be separated as the following electrochemical reactions:

$\mathrm{OH}^{-}(\mathrm{ad}) \rightarrow \mathrm{OH}(\mathrm{ad})+e^{-}$

$\mathrm{O}_{2}(\mathrm{ad})+e^{-} \rightarrow \mathrm{O}_{2}^{--}(\mathrm{ad})$

In turn, the half-cell reduction potentials of these two reactions are:

$E_{\mathrm{OH} / \mathrm{OH}^{-}}=E_{\mathrm{OH} / \mathrm{OH}^{-}}^{0}-\frac{R T}{F} \ln \left(\frac{\Gamma_{\mathrm{OH}^{-}}}{\Gamma_{\mathrm{OH}}}\right)$

$E_{\mathrm{O}_{2} / \mathrm{O}_{2}^{-}}=E_{\mathrm{O}_{2} / \mathrm{O}_{2}^{--}}^{0}-\frac{R T}{F} \ln \left(\frac{\Gamma_{\mathrm{O}_{2}^{--}}}{\Gamma_{\mathrm{O}_{2}}}\right)$

where $\Gamma$ represents the surface coverage. The cell potential $\left(E_{\text {cell }}\right)$ is:

$E_{\text {cell }}=E_{\mathrm{O}_{2} / \mathrm{O}_{2}^{-}}-E_{\mathrm{OH} \mathrm{OH}^{-}}+\frac{R T}{F} \ln \left(\frac{\Gamma_{\mathrm{O}_{2}} \Gamma_{\mathrm{OH}^{-}}}{\Gamma_{\mathrm{O}_{2}^{-}} \Gamma_{\mathrm{OH}}}\right)$

Eq. (20) tells us that $E_{\text {cell }}$ increases when $\Gamma_{\mathrm{OH}^{-}}$increases, as is the case at negative $\Delta_{0}^{\mathrm{w}} \phi$, especially when the aqueous phase is more alkaline. If $E_{\text {cell }}$ increases, then the Gibbs free energy of reaction decreases and reaction (11) is more likely to occur.

The analysis in Sections 2.5 and 2.6 establishes that the oxidation of the AuNPs in the film at the $\mathrm{L} \mid \mathrm{L}$ interface, i.e., the formation of $\mathrm{OH}(\mathrm{ad})$ by $\mathrm{O}_{2}$, proceeds independently of whether $\mathrm{O}_{2}$ is dissolved in the aqueous or organic phase. As noted vide supra, the peaks observed in Fig. $3 \mathrm{~A}$ are due to the adsorption/desorption of $\mathrm{OH}^{-}$. The peak height due to $\mathrm{OH}^{-}$adsorption (negative peak) is higher than that of $\mathrm{OH}^{-}$desorption in the presence of $\mathrm{O}_{2}$ (Fig. $3 \mathrm{~A}$, red $\mathrm{CV}$ ) as surface chemical reactions between $\mathrm{O}_{2}$, AuNPs and $\mathrm{OH}^{-}$ reduce $\Gamma_{\mathrm{OH}^{-}}$. At very positive $\Delta_{\mathrm{o}}^{\mathrm{w}} \phi, E_{\mathrm{F}}$ (AuNPs) lowers enough to promote the reduction of the gold surface possibly through the following chemical reaction:

$\mathrm{Au}-\mathrm{OH}+\mathrm{H}_{2} \mathrm{O} \rightarrow \mathrm{Au}+\mathrm{H}_{2} \mathrm{O}_{2}$

A final observation from Fig. $3 \mathrm{~A}$ is that the total charge scanning negatively is higher than that scanning in the positive direction. This suggests that the gold surface has to be re-reduced to a certain degree by a process that does not involve interfacial ion or electron transfer reactions, such as reaction (21).

2.7. Monitoring electron transfer between organic solublised $S_{8}$ and aqueous $\mathrm{O}_{2}$, catalysed by gold, using a closed bipolar electrochemical cell (CPBEC) in a 4-electrode configuration

The configuration of the 4-electrode CBPEC studied is shown in Scheme 2 and a detailed description of the setup is provided in the Experimental Methods (see SI) and Fig. S2. Each pole of the bipolar electrode consisted of a polycrystalline gold electrode, one pole immersed in the aqueous phase $\left(\mathrm{P}_{\mathrm{w}}\right)$ and the other in the organic phase $\left(\mathrm{P}_{0}\right)$.

Control CVs with the CBPEC in the absence of $S_{8}$ in the organic phase were carried out to probe the influence of gold surface redox reactions at $\mathrm{P}_{\mathrm{w}}$ and/or $\mathrm{P}_{\mathrm{o}}$ on the electrochemical response in the presence or absence of $\mathrm{O}_{2}$ in either phase (Fig. 6A). Under anaerobic conditions in each phase (Fig. 6A, dashed line), small shoulders were observed at the positive and negative edges of the potential window and attributed to electron flow due to simulateous oxidation of one gold pole and reduction of gold oxides at the other pole. Some current may also flow due to residual $\mathrm{O}_{2}$ present in either phase. When the aqueous compartment only was saturated with $\mathrm{O}_{2}$ (Fig. $6 \mathrm{~A}$, red line), the current at positive potentials increased due to electron flow along the bipolar electrode from $\mathrm{P}_{0}$ to $\mathrm{P}_{\mathrm{w}}$ leading to $\mathrm{O}_{2}$ reduction at $\mathrm{P}_{\mathrm{w}}$. Conversely, when the organic 


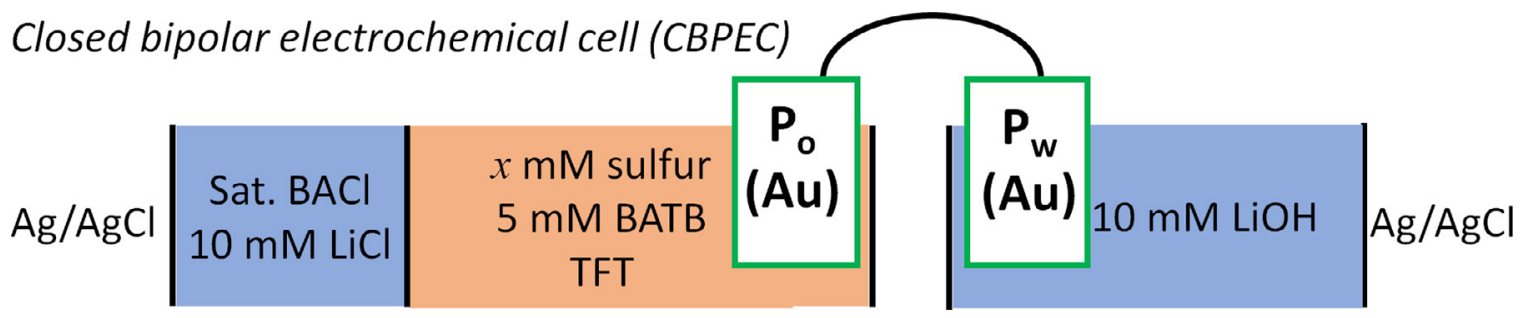

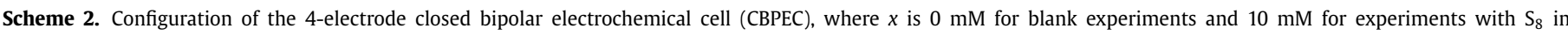

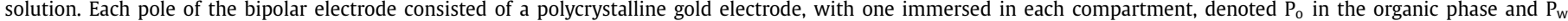

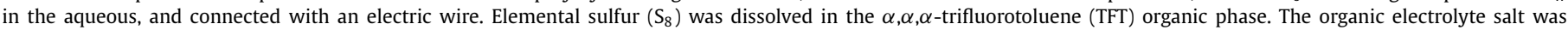

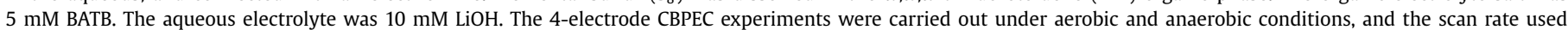
was $25 \mathrm{mV} \cdot \mathrm{s}^{-1}$.
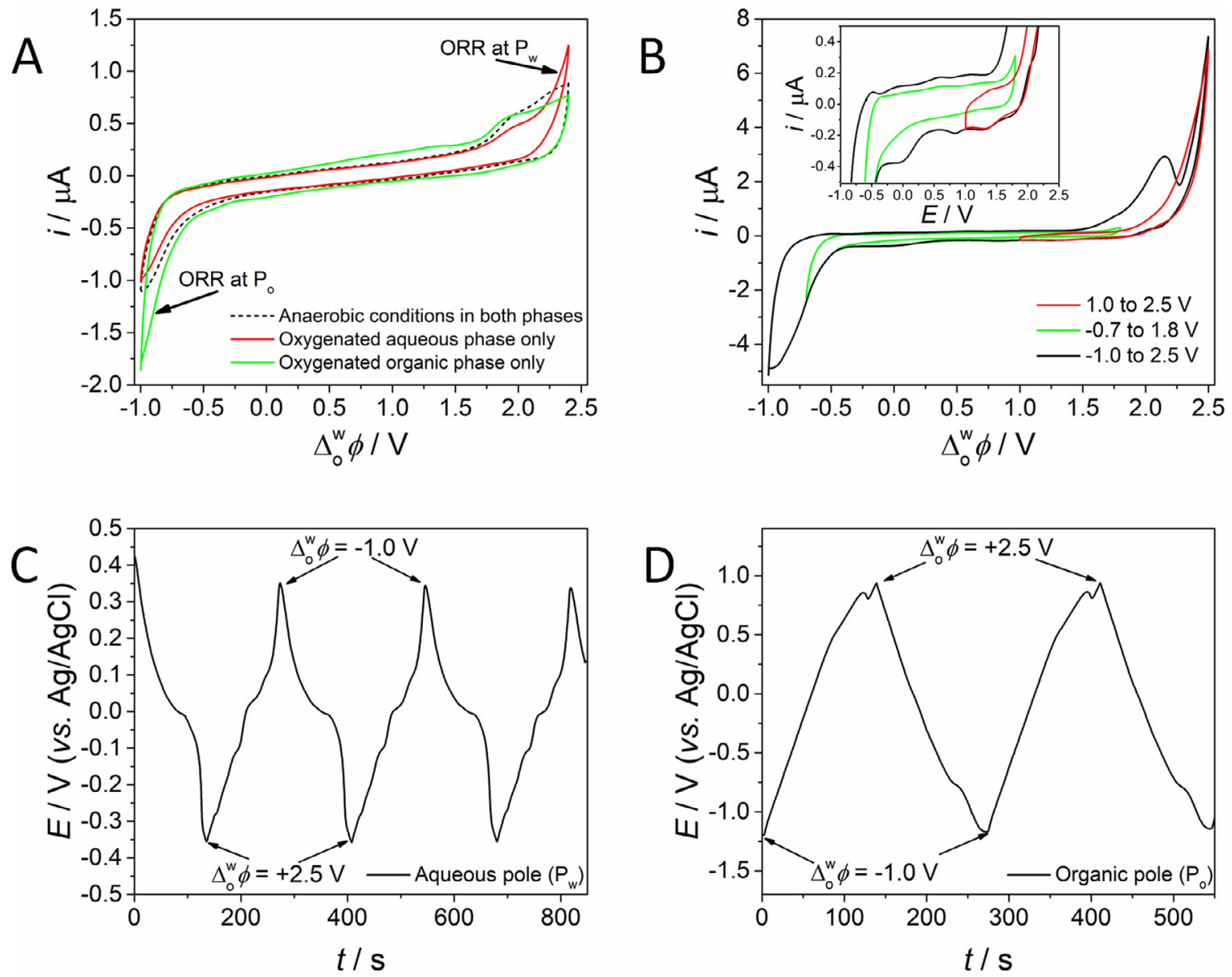

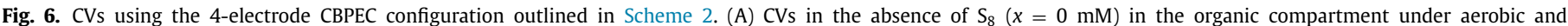

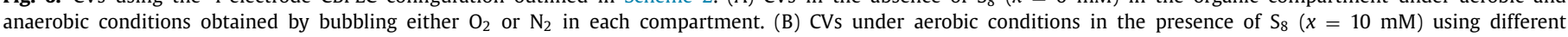

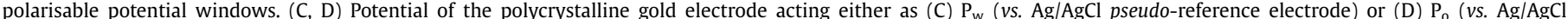

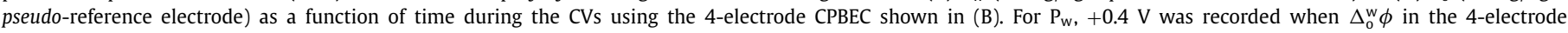

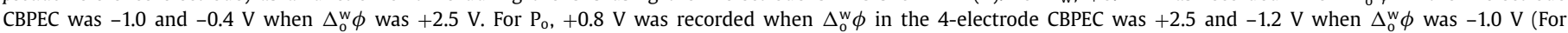
interpretation of the references to color in this figure, the reader is referred to the web version of this article.).

compartment only was saturated with $\mathrm{O}_{2}$ (Fig. $6 \mathrm{~A}$, green line), the current at negative potentials increased due to electron flow from $\mathrm{P}_{\mathrm{w}}$ to $\mathrm{P}_{\mathrm{o}}$ leading to $\mathrm{O}_{2}$ reduction at $\mathrm{P}_{0}$. Thus, $\mathrm{O}_{2}$ can be reduced in the CBPEC at $\mathrm{P}_{\mathrm{w}}$ or $\mathrm{P}_{\mathrm{o}}$ depending on the electrochemical potential of $\mathrm{O}_{2}$ at each pole of the bipolar electrode. The latter is in accordance with the insights from Sections 2.5 and 2.6 that oxidation of the AuNPs in the film at the L/L interface proceeds independently of whether $\mathrm{O}_{2}$ is dissolved in the aqueous or organic phase.

Replicating the experimental conditions at the ITIES in Fig. 5D, $\mathrm{CV}$ s were obtained with the CBPEC in the presence of $\mathrm{S}_{8}$ in the organic phase under aerobic conditions in both phases (Fig. 6B).
The currents measured in Fig 6B were much higher than those observed in the absence of $S_{8}$ (Fig. $6 \mathrm{~A}$ ) due to redox reactions involving $\mathrm{S}_{8}$ at the bipolar electrode in the CBPEC, as seen previously at the ITIES (Fig. 5D). Additionally, the shapes of the CVs shown in Figs. 6B (black line) and 5D are comparable, suggesting that similar redox processes may be taking place. However, at the ITIES the overpotential needed to observe these redox signals is much lower, confirming the electrocatalytic properties of the interfacial AuNP film towards redox reactions between $\mathrm{S}_{8}$ and $\mathrm{O}_{2}$. Furthermore, several surface processes occurring on the bipolar electrode were found to be potential-dependent. For instance, 


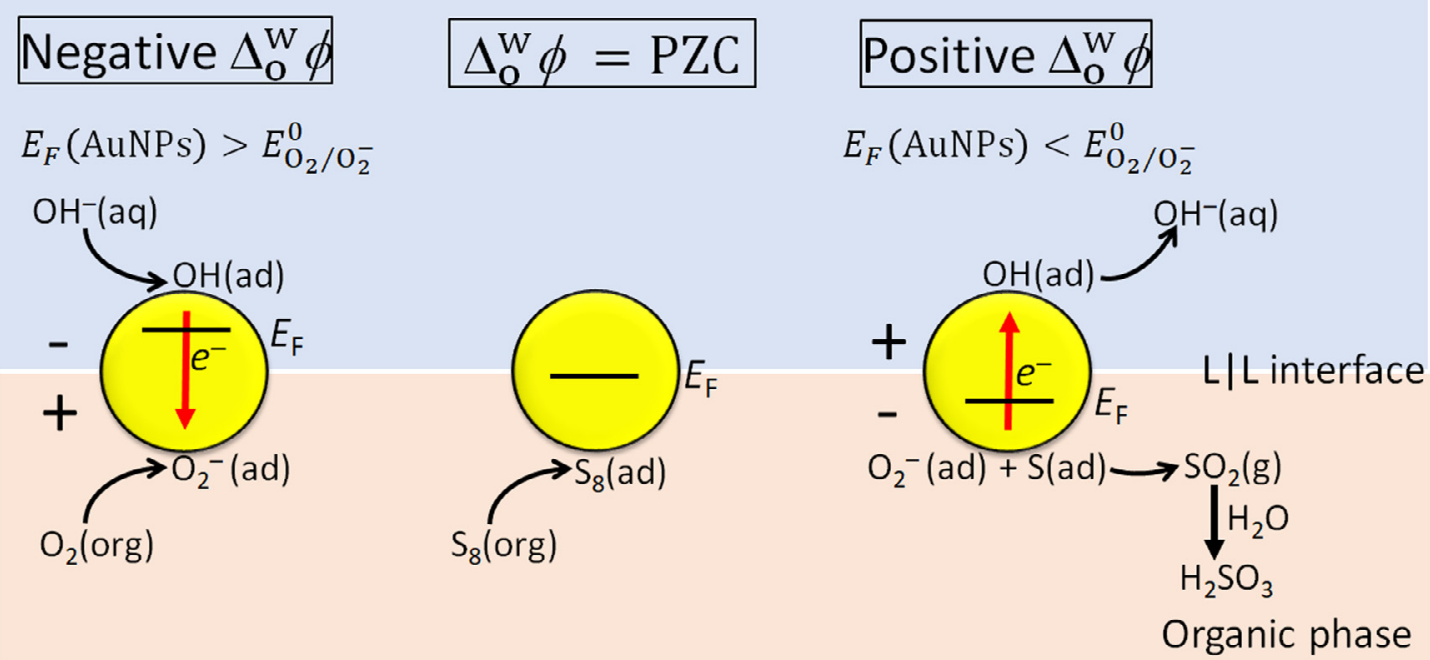

\section{ANAEROBIC CONDITIONS}

Aqueous phase
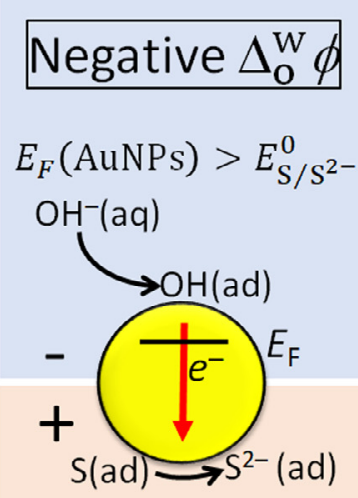
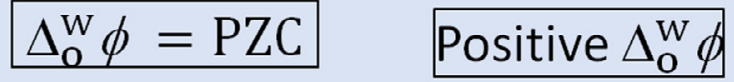

$$
E_{F} \text { (AuNPs) }<E_{\mathrm{SO}_{3}^{2-} / \mathrm{S}^{2-}}^{0}
$$

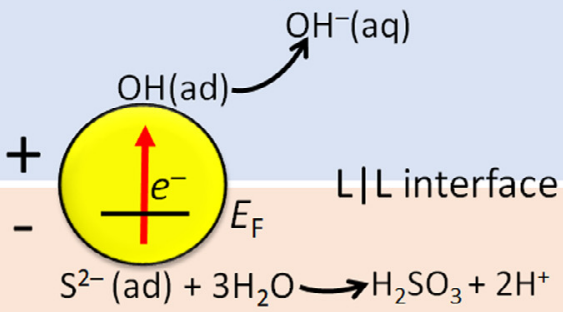

Organic phase

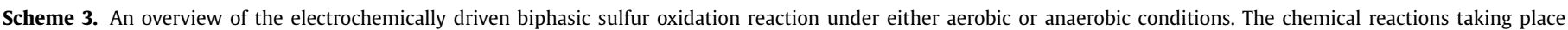

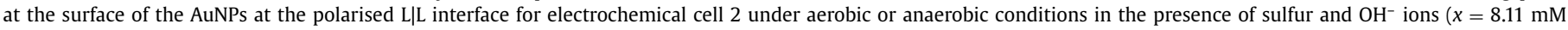
and $X=\mathrm{OH}^{-}$, see Scheme 1) are illustrated when the interfacial Galvani potential difference $\left(\Delta_{0}^{\mathrm{w}} \phi\right)$ is polarised negatively, positively or equal to the PZC.

the peak centred at $+2.15 \mathrm{~V}$ only appeared when the negative potential edge reached $-1.0 \mathrm{~V}$ (Fig. 6B, black line). This infers that at $-1.0 \mathrm{~V}$ a pre-conditioning step was needed to enhance the ORR at positive potentials. This pre-conditioning step may be attributed to the adsorption of $\mathrm{S}_{8}$ species on the surface of $\mathrm{P}_{0}$. Conversely, negative peaks centred at $-0.02,+0.82$ and $+1.31 \mathrm{~V}$ appeared when the electron transfer reaction between sulfur species and $\mathrm{O}_{2}$ had taken place at the positive edge of the potential window (see inset of Fig. $6 \mathrm{~B}$, black line). These negative peaks may be attributed to the oxidation of $S_{8}$ derivatives adsorbed on $P_{0}$. It is worth noting that the intensity of these peaks increased with successive CV scans, suggesting a constant increase of adsorbed species. Oncemore, these results agree with the proposed reaction mechanism outlined in Sections 2.5 and 2.6.

$\mathrm{P}_{\mathrm{w}}$ and $\mathrm{P}_{\mathrm{o}}$ experience different polarisable potential windows during the external bias, as shown in Figs. $6 \mathrm{C}$ and D, respectively.
The potential window at $\mathrm{P}_{\mathrm{w}}$ spans a much shorter range than that at $P_{0}$ as the aqueous and organic phases have different conductivities, with a more significant $i R$ drop experienced in the organic phase [55]. For instance, when the applied $\Delta_{0}^{\mathrm{w}} \phi$ in the CBPEC was $+2.5 \mathrm{~V}$, the potentials experienced by $\mathrm{P}_{\mathrm{w}}$ and $\mathrm{P}_{\mathrm{o}}$ were -0.4 and $+1.0 \mathrm{~V}$ versus a $\mathrm{Ag}^{+} / \mathrm{Ag}$ pseudo-reference electrode, respectively (Figs. 6C and D). At $-0.4 \mathrm{~V}$ the ORR takes place at $\mathrm{P}_{\mathrm{w}}$ (see Fig. $\mathrm{S} 3 \mathrm{~A})$, while at $+1.0 \mathrm{~V}$ some oxidation reactions are taking place at $\mathrm{P}_{\mathrm{o}}$ (see Fig. S3B). The latter may be the oxidation of sulfur species produced at negative potentials. To our knowledge, the direct electrochemical oxidation of $\mathrm{S}_{8}$ when it is dissolved in organic solvents has not been reported previously. When the applied $\Delta_{0}^{\mathrm{w}} \phi$ in the CBPEC was $-1.0 \mathrm{~V}$, the potentials experienced by $\mathrm{P}_{\mathrm{w}}$ and $\mathrm{P}_{0}$ were +0.4 and $-1.0 \mathrm{~V}$ versus a $\mathrm{Ag}^{+} / \mathrm{Ag}$ pseudo-reference electrode, respectively (Figs. $6 \mathrm{C}$ and $\mathrm{D}$ ). At $+0.4 \mathrm{~V}$, the oxidation of $\mathrm{P}_{\mathrm{w}}$ can take place in the aqueous compartment (see Fig. S3A), while sev- 
eral reduction reactions are feasible at $\mathrm{P}_{\mathrm{o}}$ (see Fig. S3B), such as $\mathrm{O}_{2}$ [56] and/or $S_{8}$ [57] reduction. These results support the idea that gold oxides and/or hydroxides can act as redox intermediaries for the redox reaction between $\mathrm{S}_{8}$ and $\mathrm{O}_{2}$ upon potential cycling at the ITIES (Fig. 5D).

\subsection{Reaction mechanism of the oxidation of $\mathrm{S}_{8}$ by $\mathrm{O}_{2}$ at the ITIES}

Our proposed mechanism of the electrochemically driven biphasic sulfur oxidation reaction catalysed by AuNPs deposited at a polarised $\mathrm{L} \mid \mathrm{L}$ interface, under either aerobic or anaerobic conditions, is illustrated in Scheme 3.

Scheme 3 shows that the oxidation of adsorbed sulfur ( $\mathrm{S}(\mathrm{ad})$ ) and sulfide ions $\left(\mathrm{S}^{2-}(\mathrm{ad})\right)$ can take place under aerobic and anaerobic conditions, respectively. The driving force for these reactions is a positive polarisation of $\Delta_{\mathrm{o}}^{\mathrm{w}} \phi$ that can reduce $E_{\mathrm{F}}$ (AuNPs) to values lower than either $E_{\mathrm{O}_{2} / \mathrm{O}_{2}^{-}}^{0}$ under aerobic conditions or $E_{\mathrm{SO}_{3}^{2-} / \mathrm{S}^{2-}}^{0}$ under anaerobic conditions, respectively. Figs. 5D and 3B, under aerobic and anaerobic conditions, respectively, both show positive current increases at positive $\Delta_{0}^{\mathrm{w}} \phi$, supporting our hypothesis.

Whether sulfur oxidation by dissolved $\mathrm{O}_{2}$ takes place heterogeneously or homogeneously remains a matter of debate. Smirnov et al. have previously shown, by means of a CBPEC, that the ORR takes place on the aqueous side of the interfacial AuNPs in the presence of an organic electron donor species [26]. Fig. 6A shows that the ORR can happen in the aqueous or organic phase depending on the electrochemical potential of $\mathrm{O}_{2}$, or in which phases the oxidising and reducing agents are dissolved. However, it should be noted that there is no truly definitive experimental evidence in the literature as to whether the ORR mechanism is homogeneous or heterogeneous, or if the ORR takes place in the organic or aqueous phase in the presence of catalysts adsorbed at the L/L interface [58]. The standard reduction potentials and high $\mathrm{O}_{2}$ solubility in organic solvents favour the hydrogen evolution reaction (HER) and ORR, via either the 2- or 4-electron pathway, taking place in the organic phase [58]. However, the concentration of protons, which are needed for the reduction of $\mathrm{O}_{2}$ to water, in aprotic organic solvents is extremely low. Furthermore, while thermodynamically favoured, the kinetics of the HER and ORR in the organic phase may be slow due to its low permittivity constant. The electrochemical reactions occur with higher rates in solvents with higher permittivity constants, i.e., aqueous solutions.

\section{Conclusions}

In this article, a novel methodology to form an interfacial film of AuNPs at a polarised L/L interface is developed. By employing PBS modified AuNPs, potential cycling yields a homogeneous film of interfacial AuNPs. Electrochemistry at a polarised $\mathrm{L} \mid \mathrm{L}$ interface also provides a means of monitoring the adsorption of electrolyte species (herein $\mathrm{Cl}^{-}$and $\mathrm{OH}^{-}$anions) on the interfacial AuNPs and driving catalytic redox reactions at the AuNP's surface (herein $\mathrm{S}_{8}$ oxidation by $\mathrm{O}_{2}$ ). Modelling of the $\mathrm{CV}$ data shows that the adsorption of anions can be reasonably described by a Frumkin model, the anion-Au bond must be highly polar and the anions are physisorbed on the interfacial AuNPs (a new insight). The homogeneous oxidation of $\mathrm{S}_{8}$ at low temperatures is unlikely in a homogeneous phase as the reactants, intermediates and products have different solubility properties. The biphasic system overcomes these solubility limitations, while simultaneously providing an electrochemically controlled catalytic interface. Importantly, differential capacitance measurements provide evidence that $S_{8}$ adsorbs on the interfacial AuNPs. The electrochemical signals attributed to $S_{8}$ oxidation by $\mathrm{O}_{2}$ were enhanced when $\mathrm{LiOH}$ was used as the aqueous electrolyte. The $\mathrm{OH}^{-}$anions have multiple roles in the mechanism, raising the Fermi level of AuNPs upon adsorption, enhancing $\mathrm{O}_{2}$ adsorption on the AuNPs, and acting as an intermediary and source of oxygen atoms. Experiments with a closed bipolar electrochemical cell confirm that electron transfer reactions can occur through the gold bipolar electrode between $\mathrm{S}_{8}$ (and its derivatives) and $\mathrm{O}_{2}$. The closed bipolar electrochemical cell experiments demonstrate that gold is an effective electrocatalyst for this reaction and acts as a redox intermediary. To our knowledge, this is the first report of an artificial system that can mimic the microbial oxidation of elemental sulfur at ambient conditions.

\section{Declaration of Competing Interest}

The authors declare that they have no known competing financial interests or personal relationships that could have appeared to influence the work reported in this paper.

\section{Credit authorship contribution statement}

Marco F. Suárez-Herrera: Investigation, Methodology, Writing - original draft. Alonso Gamero-Quijano: Investigation, Methodology, Writing - review \& editing. José Solla-Gullón: Methodology, Writing - review \& editing. Micheál D. Scanlon: Methodology, Project administration, Writing - review \& editing, Funding acquisition.

\section{Acknowledgments}

M.D.S. acknowledges Science Foundation Ireland (SFI), under Grant No. 13/SIRG/2137 and the European Research Council through a Starting Grant (Agreement No. 716792). A.G.-Q. acknowledges an Irish Research Council (IRC) Government of Ireland Postdoctoral Fellowship (GOIPD/2018/252). M.F.S.-H. acknowledges the "Universidad Nacional de Colombia" for allowing his sabbatical leave and the "Fundación Banco de la República" through the grant 4.562 .

\section{Supplementary materials}

Supplementary material associated with this article can be found, in the online version, at doi:10.1016/j.electacta.2021.139443.

\section{References}

[1] L. Ahonen, O.H. Tuovinen, Kinetics of sulfur oxidation at suboptimal temperatures, Appl. Environ. Microbiol. 56 (1990) 560-562.

[2] D.E. Canfield, The evolution of the sulfur cycle, Am. J. Sci. 299 (1999) 697-723, doi:10.2475/ajs.299.7-9.697.

[3] B.J. Little, R.I. Ray, R.K. Pope, The relationship between corrosion and the biological sulfur cycle, NACE Int. Corros. Conf. Ser. 56 (2000) 433-443 2000-March.

[4] A. Deubel, H. Braune, H. Tanneberg, W. Merbach, Conversion and acidifying effect of elemental sulphur in an alkaline loess soil, Arch. Agron. Soil Sci. 53 (2007) 161-171, doi:10.1080/03650340601124933.

[5] H.H. Karamanos, R. E.Janzen, Short-term and residual contribution of selected elemental S fertilizers to the S fertility of two Luvisolic soils, Can. J. Soil Sci. 71 (1991) 203-211, doi:10.4141/cjss91-020.

[6] S.S. Malhi, Influence of four successive annual applications of elemental S and sulphate-S fertilizers on yield, S uptake and seed quality of canola, Can. J. Plant Sci. 85 (2005) 777-792, doi:10.4141/P04-133.

[7] J. Boulegue, Solubility of elemental sulfur in water at $298 \mathrm{~K}$, Phosphorus Sulfur Relat. Elem. 5 (1978) 127-128, doi:10.1080/03086647808069875.

[8] V. Beschkov, E. Razkazova-Velkova, M. Martinov, S. Stefanov, Electricity production from marine water by sulfide-driven fuel cell, Appl. Sci. 8 (2018) 1926, doi:10.3390/app8101926

[9] N.V. Richardson, P. Weinberger, The electronic structure of the S8 molecule, J. Electron Spectros. Relat. Phenom. 6 (1975) 109-116, doi:10.1016/0368-2048(75)80003-X.

[10] R. Steudel, G. Holdt, Solubilization of elemental sulfur in water by cationic and anionic surfactants, Angew. Chem. Int. Ed. Engl. 27 (1988) 1358-1359, doi:10. 1002/anie.198813581

[11] P. Turina, J. Petersen, P. Gräber, Thermodynamics of proton transport coupled ATP synthesis, Biochim. Biophys. Acta Bioenerg. 1857 (2016) 653-664, doi:10. 1016/j.bbabio.2016.02.019. 
[12] M.F. Suárez-Herrera, M.D. Scanlon, On the non-ideal behaviour of polarised liquid-liquid interfaces, Electrochim. Acta 328 (2019) 1-9, doi:10.1016/ j.electacta.2019.135110.

[13] G.C. Gschwend, A. Olaya, H.H. Girault, How to polarise an interface with ions: the discrete Helmholtz model, Chem. Sci. 11 (2020) 10807-10813, doi:10.1039/ d0sc00685h.

[14] G.C. Gschwend, A. Olaya, P. Peljo, H.H. Girault, Structure and reactivity of the polarised liquid-liquid interface: what we know and what we do not, Curr. Opin. Electrochem. 19 (2020) 137-143, doi:10.1016/j.coelec.2019.12.002.

[15] Z. Samec, Electrochemistry at the interface between two immiscible electrolyte solutions (IUPAC technical report), Pure Appl. Chem. 76 (2004) 2147-2180, doi:10.1351/pac200476122147.

[16] J.J. Germida, H.H. Janzen, Factors affecting the oxidation of elemental sulfur in soils, Fertil. Res. 35 (1993) 101-114, doi:10.1007/BF00750224.

[17] A. Corma, H. Garcia, Supported gold nanoparticles as catalysts for organic reactions, Chem. Soc. Rev. 37 (2008) 2096-2126, doi:10.1039/b707314n.

[18] T. Fujita, P. Guan, K. McKenna, X. Lang, A. Hirata, L. Zhang, T. Tokunaga, S. Arai, Y. Yamamoto, N. Tanaka, Y. Ishikawa, N. Asao, Y. Yamamoto, J. Erlebacher, M. Chen, Atomic origins of the high catalytic activity of nanoporous gold, Nat. Mater. 11 (2012) 775-780, doi:10.1038/nmat3391.

[19] Y. Xu, M. Mavrikakis, Adsorption and dissociation of $\mathrm{O}_{2}$ on gold surfaces: effect of steps and strain, J. Phys. Chem. B 107 (2003) 9298-9307, doi:10.1021/ jp034380x.

[20] M.S. Ide, R.J. Davis, The important role of hydroxyl on oxidation catalysis by gold nanoparticles, Acc. Chem. Res. 47 (2014) 825-833, doi:10.1021/ar4001907.

[21] B.E. Hayden, D. Pletcher, M.E. Rendall, J.P. Suchsland, CO oxidation on gold in acidic environments: particle size and substrate effects, J. Phys. Chem. C 111 (2007) 17044-17051, doi:10.1021/jp074651u.

[22] M.D. Scanlon, P. Peljo, M.A. Méndez, E. Smirnov, H.H. Girault, Charging and discharging at the nanoscale: fermi level equilibration of metallic nanoparticles, Chem. Sci. 6 (2015) 2705-2720, doi:10.1039/C5SC00461F.

[23] E. Smirnov, P. Peljo, M.D. Scanlon, H.H. Girault, Interfacial redox catalysis on gold nanofilms at soft interfaces, ACS Nano 9 (2015) 6565-6575, doi:10.1021/ acsnano.5b02547.

[24] P. Peljo, M.D. Scanlon, A.J. Olaya, L. Rivier, E. Smirnov, H.H. Girault, Redox electrocatalysis of floating nanoparticles: determining electrocatalytic properties without the influence of solid supports, J. Phys. Chem. Lett. 8 (2017) 35643575, doi:10.1021/acs.jpclett.7b00685.

[25] M.D. Scanlon, E. Smirnov, T.J. Stockmann, P. Peljo, Gold nanofilms at liquidliquid interfaces: an emerging platform for redox electrocatalysis, nanoplasmonic sensors, and electrovariable optics, Chem. Rev. 118 (2018) 3722-3751, doi:10.1021/acs.chemrev.7b00595.

[26] E. Smirnov, P. Peljo, M.D. Scanlon, H.H. Girault, Gold nanofilm redox catalysis for oxygen reduction at soft interfaces, Electrochim. Acta 197 (2016) 362-373, doi:10.1016/j.electacta.2015.10.104

[27] C. Li, Y. Xu, X. Li, Z. Ye, C. Yao, Q. Chen, Y. Zhang, S.E.J. Bell, Unexpected dual action of cetyltrimethylammonium bromide (CTAB) in the self-assembly of colloidal nanoparticles at liquid-liquid interfaces, Adv. Mater. Interfaces 7 (2020) 2000391, doi:10.1002/admi.202000391.

[28] Y. Montelongo, D. Sikdar, Y. Ma, A.J.S. McIntosh, L. Velleman, A.R. Kucernak, J.B. Edel, A.A. Kornyshev, Electrotunable nanoplasmonic liquid mirror, Nat. Mater. 16 (2017) 1127-1135, doi:10.1038/NMAT4969.

[29] G.C. Gschwend, E. Smirnov, P. Peljo, H.H. Girault, Electrovariable gold nanoparticle films at liquid-liquid interfaces: from redox electrocatalysis to marangonishutters, Faraday Discuss. 199 (2017) 565-583, doi:10.1039/c6fd00238b.

[30] D.B. Grys, B. De Nijs, A.R. Salmon, J. Huang, W. Wang, W.H. Chen, O.A. Scherman, J.J. Baumberg, Citrate coordination and bridging of gold nanoparticles: the role of gold adatoms in AuNP aging, ACS Nano 14 (2020) 8689-8696, doi:10.1021/acsnano.0c03050.

[31] R. McGorty, J. Fung, D. Kaz, V.N. Manoharan, Colloidal self-assembly at an interface, Mater. Today. 13 (2010) 34-42, doi:10.1016/S1369-7021(10)70107-3.

[32] T. Ding, A.W. Rudrum, L.O. Herrmann, V. Turek, J.J. Baumberg, Polymer-assisted self-assembly of gold nanoparticle monolayers and their dynamical switching, Nanoscale 8 (2016) 15864-15869, doi:10.1039/c6nr05199e.

[33] H. Duan, D. Wang, D.G. Kurth, H. Möhwald, Directing self-assembly of nanoparticles at water/oil interfaces, Angew. Chem. Int. Ed. 43 (2004) 5639-5642, doi:10.1002/anie.200460920.

[34] L. Velleman, D. Sikdar, V.A. Turek, A.R. Kucernak, S.J. Roser, A.A. Kornyshev, J.B. Edel, Tuneable 2D self-assembly of plasmonic nanoparticles at liquid|liquid interfaces, Nanoscale 8 (2016) 19229-19241, doi:10.1039/c6nr05081f.

[35] Y. Xu, M.P. Konrad, W.W.Y. Lee, Z. Ye, S.E.J. Bell, A method for promoting assembly of metallic and nonmetallic nanoparticles into interfacial monolayer films, Nano Lett. 16 (2016) 5255-5260, doi:10.1021/acs.nanolett.6b02418.
[36] M.P. Konrad, A.P. Doherty, S.E.J. Bell, Stable and uniform SERS signals from selfassembled two-dimensional interfacial arrays of optically coupled Ag nanoparticles, Anal. Chem. 85 (2013) 6783-6789, doi:10.1021/ac4008607.

[37] A. Chen, J. Lipkowski, Electrochemical and spectroscopic studies of hydroxide adsorption at the Au(111) electrode, J. Phys. Chem. B 103 (1999) 682-691, doi:10.1021/jp9836372.

[38] M.F. Suárez-Herrera, M.D. Scanlon, Quantitative analysis of redox-inactive ions by AC voltammetry at a polarized interface between two immiscible electrolyte solutions, Anal. Chem. 92 (2020) 10521-10530, doi:10.1021/acs. analchem.0c01340.

[39] T. Pajkossy, Impedance spectroscopy at interfaces of metals and aqueous solutions -surface roughness, CPE and related issues, Solid State Ion. 176 (2005) 1997-2003, doi:10.1016/j.ssi.2004.06.023.

[40] P. Cördoba-Torres, T.J. Mesquita, R.P. Nogueira, Relationship between the origin of constant-phase element behavior in electrochemical impedance spectroscopy and electrode surface structure, J. Phys. Chem. C 119 (2015) 41364147, doi:10.1021/jp512063f.

[41] T. Pajkossy, R. Jurczakowski, Electrochemical impedance spectroscopy in interfacial studies, Curr. Opin. Electrochem. 1 (2017) 53-58, doi:10.1016/j.coelec. 2017.01.006.

[42] N. Younan, M. Hojeij, L. Ribeaucourt, H.H. Girault, Electrochemical properties of gold nanoparticles assembly at polarised liquid|liquid interfaces, Electrochem. Commun. 12 (2010) 912-915, doi:10.1016/j.elecom.2010.04.019.

[43] I.C. Hamilton, R. Woods, An investigation of the deposition and reactions of sulphur on gold electrodes, J. Appl. Electrochem. 13 (1983) 783-794, doi:10. 1007/BF00615828.

[44] A. Briceno, S. Chander, Oxidation of hydrosulphide ions on gold part I: a cyclic voltammetry study, J. Appl. Electrochem. 20 (1990) 506-511, doi:10. 1007/BF01076064.

[45] A. Briceno, S. Chander, Oxidation of hydrosulphide ions on gold part II: characterization of gold/aqueous hydrosulphide solution interface, J. Appl. Electrochem. 20 (1990) 512-517, doi:10.1007/BF01076065.

[46] H. Tada, T. Soejima, S. Ito, H. Kobayashi, Photoinduced desorption of sulfur from gold nanoparticles loaded on metal oxide surfaces, J. Am. Chem. Soc. 126 (2004) 15952-15953, doi:10.1021/ja0449980.

[47] K.A. Assiongbon, D. Roy, Electro-oxidation of methanol on gold in alkaline media: adsorption characteristics of reaction intermediates studied using time resolved electro-chemical impedance and surface plasmon resonance techniques, Surf. Sci. 594 (2005) 99-119, doi:10.1016/j.susc.2005.07.015.

[48] R. Garrels, C. Naeser, Equilibrium distribution of dissolved sulphur species in water at $25^{\circ} \mathrm{C}$ and $1 \mathrm{~atm}$ total pressure, Geochim. Cosmochim. Acta 15 (1958) 113-130, doi:10.1016/0016-7037(58)90014-0.

[49] D. Rickard, Sulfidic sediments and sedimentary rocks, 1st ed., Elsevier, 2012.

[50] Y.F. Huang, M. Zhang, L. Bin Zhao, J.M. Feng, D.Y. Wu, B. Ren, Z.Q. Tian, Activation of oxygen on gold and silver nanoparticles assisted by surface plasmon resonances, Angew. Chem. Int. Ed. 53 (2014) 2353-2357, doi:10.1002/anie. 201310097.

[51] A. Sanchez, S. Abbet, U. Heiz, W.D. Schneider, H. Häkkinen, R.N. Barnett, U. Landman, When gold is not noble: nanoscale gold catalysts, J. Phys. Chem. A 103 (1999) 9573-9578, doi:10.1021/jp9935992.

[52] N. Ohta, K. Nomura, I. Yagi, Adsorption and electroreduction of oxygen on gold in acidic media: in situ spectroscopic identification of adsorbed molecular oxygen and hydrogen superoxide, J. Phys. Chem. C 116 (2012) 14390-14400, doi:10.1021/jp302857q.

[53] M.H. Shao, R.R. Adzic, Spectroscopic identification of the reaction intermediates in oxygen reduction on gold in alkaline solutions, J. Phys. Chem. B 109 (2005) 16563-16566, doi:10.1021/jp053450s.

[54] R. Battino, T.R. Rettich, T. Tominaga, The solubility of oxygen and ozone in liquids, J. Phys. Chem. Ref. Data 12 (1983) 163-178, doi:10.1063/1.555680.

[55] A. Gamero-Quijano, A.F. Molina-Osorio, P. Peljo, M.D. Scanlon, Closed bipolar electrochemistry in a four-electrode configuration, Phys. Chem. Chem. Phys. 21 (2019) 9627-9640, doi:10.1039/С9СР00774A.

[56] D. Vasudevan, H. Wendt, Electroreduction of oxygen in aprotic media, J. Electroanal. Chem. 392 (1995) 69-74, doi:10.1016/0022-0728(95)04044-0.

[57] F. Gaillard, E. Levillain, Visible time-resolved spectroelectrochemistry: application to study of the reduction of sulfur (S8) in dimethylformamide, J. Electroanal. Chem. 398 (1995) 77-87, doi:10.1016/0022-0728(95)04144-1.

[58] A.N.J. Rodgers, S.G. Booth, R.A.W. Dryfe, Particle deposition and catalysis at the interface between two immiscible electrolyte solutions (ITIES): a mini-review, Electrochem. Commun. 47 (2014) 17-20, doi:10.1016/j.elecom.2014.07.009. 